\title{
La relación causa-efecto entre exclusión/inclusión social y financiera. Una aproximación teórica
}

\author{
Angela María Padilla Sánchez ${ }^{1}$ y Joan Ramon Sanchis Palacioº
}

Recibido: 20 de enero de 2020 / Aceptado: 22 de diciembre de 2020 / Publicado: 26 de marzo de 2021

Resumen. La realidad social y económica actual representada en situaciones de vulnerabilidad y desigualdad ha dejado al descubierto tipos de exclusión que no estaban abordados en los diferentes estudios, como son los casos de la exclusión financiera y social, dado que tales conceptos eran comúnmente identificados en términos de pobreza, miseria o marginalidad, entre otros. Estas nuevas categorías de estudio dan lugar a la búsqueda de estrategias que permitan disminuir esa brecha de desigualdad, mediante el estudio de la relación entre la inclusión financiera y la inclusión social.

En esta línea, el presente trabajo tiene como propósito desarrollar una aproximación teórica que visibilice la relación causa y efecto existente entre la exclusión e inclusión social y financiera. El enfoque metodológico utilizado para tal aproximación se basa en una reflexión teórico-conceptual, fundamentada en una revisión de la literatura científica abordada alrededor de las cuatro categorías de estudio propuestas, desarrollada a partir de trabajos empíricos y teóricos que permitieron evidenciar los elementos comunes que soportan la relación conceptual. En un primer apartado conceptual se exponen los fundamentos teóricos, en el segundo se plantea el análisis teórico de la relación causa y efecto y se finaliza con los hallazgos y las limitaciones encontradas a lo largo del trabajo.

Palabras clave: Vulnerabilidad; Pobreza; Desigualdad; Desarrollo; Calidad de vida.

Claves Econlit: A13; G21; O15.

\section{[en] The cause-effect relationship between social and financial exclusion/inclusion. A theoretical approach}

\begin{abstract}
The current social and economic reality represented in situations of vulnerability and inequality has exposed types of exclusion that were not addressed in the different studies, such as cases of financial and social exclusion, given that such concepts were commonly identified with terms such as poverty, misery or marginality, among others. These new categories of study give rise to the search for strategies that allow to reduce this inequality gap, by studying the relationship between financial inclusion and social inclusion.

In this line, the present work aims to develop a theoretical approach that makes visible the cause and effect relationship between social and financial exclusion and inclusion. The methodological approach used for such an approach is based on a theoretical-conceptual reflection, based on a review of the scientific literature addressed around the four proposed study categories, developed from empirical and theoretical works that allowed to demonstrate the common elements that support the conceptual relationship. In the first conceptual section the theoretical foundations are exposed, in the second the theoretical analysis of the cause and effect relationship is presented and the findings and limitations found throughout the work are finalized.
\end{abstract}

Keywords: Vulnerability; Poverty; Inequality; Development; Quality of life.

Sumario. 1. Introducción. 2. Fundamentos Teóricos. 3. Relación conceptual causa-efecto entre la inclusión/exclusión social y financiera: análisis bibliométrico. 4. Conclusiones. 5. Referencias bibliográficas.

Cómo citar. Padilla Sánchez, A.M.; Sanchis Palacio, J.R. (2021) La relación causa-efecto entre exclusión/inclusión social y financiera. Una aproximación teórica. REVESCO. Revista de Estudios Cooperativos, vol. $138, \quad$ e69168. https://dx.doi.org/10.5209/reve.69168. 


\section{Introducción}

La actual situación económica y social ha dejado al descubierto una exclusión representada no solo en el devenir diario de las personas, que deben enfrentase a situaciones diversas para cubrir sus necesidades, sino en las estrategias y políticas que desde las instancias gubernamentales se están desarrollando. Así, en el VIII Informe Foesa de 2019 se señala que "Las políticas sociales aplicadas por los estados de bienestar europeos durante el período 2008-2018 han ido dirigidas a la reducción del déficit público y de la deuda soberana y, secundariamente, a paliar y prevenir los efectos del paro, de la pobreza y de la exclusión social" 3 . En consecuencia, la clara necesidad de buscar estrategias o alternativas que permitan disminuir la brecha de pobreza, incluso desde los análisis teóricos, nos lleva a la idea de estudiar otras categorías de análisis como son la exclusión/inclusión financiera y social, a través de las cuales poder entender mejor la realidad y dar respuesta a estos fenómenos socioeconómicos.

Dado que, desde un enfoque amplio, la exclusión financiera está conectada directamente con factores sociales y con las necesidades de algunos colectivos, desde su vulnerabilidad, pobreza y ubicación geográfica, es relevante dar respuesta a la urgencia de contar con una banca accesible a todas las personas (Anderloni et al., 2008; Allen et al., 2016). Esta banca ha de ofrecer un servicio que cubra parte de las necesidades básicas de la población, contribuyendo así a la inclusión financiera y, por ende, a la inclusión social (Sanchis, 2016). Esto se puede conseguir a partir de un sistema financiero inclusivo que sirva de herramienta para disminuir la desigualdad, al actuar como un elemento indirecto que afecta positivamente el mercado laboral, intensificando el crecimiento económico, acelerando la competencia y ampliando la demanda de mano de obra, y representando beneficios para los grupos o colectivos en condiciones de vulnerabilidad (Demirguc-Kunt y Levine, 2009). De igual manera, se consigue paliar el incremento de las fuentes informales de crédito, generar canales seguros y eficaces de ahorro, creando bienestar para quienes pueden acceder a la banca y al mismo tiempo optimizar la gestión de las finanzas en el día a día (Sarma y Pais, 2011).

El presente trabajo tiene como objetivo el desarrollo de una aproximación teórica que determine la relación causa-efecto existente entre la exclusión/inclusión financiera y la exclusión/inclusión social, abordando el análisis desde una perspectiva teórica de las cuatro categorías de estudio propuestas, dejando ver el impacto multidimensional que tienen entre ellas a partir de sus puntos coincidentes directos.

La metodología empleada en el trabajo ha consistido en una revisión bibliográfica en general para el estudio de la exclusión/inclusión financiera y social por separado, y en un análisis bibliométrico para el estudio de la relación entre ambos conceptos. A partir del análisis de los diferentes trabajos identificados, se presenta una primera aproximación teórica a las relaciones causa-efecto entre la exclusión/inclusión financiera y social, teniendo en cuenta la existencia de una relación evidente y directa entre ambos tipos de exclusión/inclusión.

Para cumplir con el propósito este documento, está desarrollado de tal manera que una vez realizada la introducción en este primer apartado, en el segundo apartado se exponen los fundamentos teóricos del trabajo, definiendo los conceptos y características de la exclusión/inclusión financiera y de la exclusión/inclusión social. En el tercer apartado se plantea el análisis teórico de la relación causa y efecto entre las cuatro categorías de conceptos mediante el análisis bibliométrico realizado y se finaliza con un apartado de conclusiones en el que se describen los hallazgos obtenidos y las limitaciones del trabajo.

\section{Fundamentos teóricos}

\subsection{Exclusión/inclusión financiera}

En lo que se refiere a las definiciones de exclusión financiera, sean conceptuales o funcionales, tienen que ver más con un fenómeno complejo y multidimensional que con un concepto que se presenta principalmente entre personas o grupos marginados de la sociedad. Dicho de otro modo, la exclusión financiera afecta invariablemente a los miembros más pobres de la sociedad, esto es, a un número significativo de personas de bajos ingresos que están aparentemente excluidos de servicios bancarios y de productos básicos como créditos, seguros, servicios de pago de facturas y cuentas de depósitos (Sarma y Pais, 2011).

No obstante, para lograr consensuar las ideas e intentar establecer una definición más exacta, a mediados de los años 90, Leyshon y Thrift (1995) empiezan a visibilizar a los grupos sociales vulnerables, pobres y desfavorecidos como los colectivos más afectados por no tener acceso al sistema financiero. Por tanto, la exclusión financiera no procede de una razón o de un proceso sencillo, dado que incluye el rechazo categórico de algunas instituciones por incluir a determinados grupos como sus clientes. No obstante, 
también se identifica a personas o colectivos que se excluyen de manera voluntaria, que eligen no tener productos financieros por diversas razones como no estar en línea con las estrategias de marketing, los costes o el diseño de producto (Kempson y Whyley, 1999; Kempson et al., 2000).

Comienzan a identificarse determinados grupos de la sociedad que por no contar con los servicios financieros básicos, no pueden obtener tampoco otras prestaciones sociales importantes para una buena calidad de vida, dado que éstas se otorgan a través del sistema bancario (Anderloni y Carluccio, 2007). De modo que la exclusión financiera es considerada como uno de los problemas relevantes que frenan el desarrollo social y económico (Gómez-Barroso y Marbán-Flores, 2013). Estos grupos excluidos, son especialmente colectivos de personas con altos niveles de pobreza, con poca formación, migrantes, desempleadas o que viven en territorios rurales. Son quienes cuentan con mayores limitaciones a la hora de acceder a los servicios y productos financieros (Allen et al., 2016).

Por tanto, merece la pena subrayar que hay exclusión financiera cuando una persona "sufre un grado de discapacidad tal que no puede vivir normalmente en la sociedad de la que es parte debido a dificultades que encuentra para acceder a la utilización de ciertos medios de abono o pago, a ciertas formas de préstamo o financiación, a preservar su ahorro o a asegurarse contra el riesgo de la existencia" (Servet, 2001; en Zubeldia et al., 2008: 209). Son muchos los autores que definen la exclusión financiera desde este punto de vista (Cull et al., 2014; Allen et al., 2016; Ampudia y Ehrmann; 2016; Iqbal y Sami, 2017; Arora, 2018).

Según lo señalado en los párrafos anteriores, la exclusión financiera puede ser considerada como un fenómeno social. Los obstáculos para acceder a créditos, cuentas y el endeudamiento son aspectos que pueden incrementar la exclusión social. Por lo que la exclusión financiera debe plantearse desde las consecuencias sociales a los problemas de uso y acceso y no desde la responsabilidad de bancos o clientes (Servet, 2001). Más aún teniendo en cuenta que los obstáculos que representa la exclusión financiera están vinculados a que las transacciones financieras estén ubicadas en el centro de la sociedad y de las relaciones; dicho de otro modo, muchas de las acciones del día a día giran en torno a las operaciones bancarias, por lo que se convierten casi en imprescindibles para vivir en sociedad con calidad de vida (Gloukoviezoff, 2007).

Es relevante considerar lo señalado por algunos autores en referencia a las diferencias que existen entre el uso y el acceso a los servicios financieros. En este sentido, Fernández-Olit (2016) destaca la importancia de delimitar el concepto considerando estos dos aspectos, especialmente por la incidencia entre los colectivos afectados. Asimismo, es necesario enfatizar en los grados de uso que las personas le dan a los servicios financieros, teniendo en cuenta que hay quienes eligen no usarlos por las mismas razones por las que a otras personas o colectivos les es negado el acceso (Anderloni et al., 2008).

En el mismo sentido, Gloukoviezoff (2007) señala que estar excluido financieramente no se refiere solamente a no poder acceder a los servicios bancarios. Estar bancarizado o no tiene que ver especialmente con la influencia que tienen las dificultades de uso y acceso y de las consecuencias sociales de estas dificultades. El autor destaca que las limitaciones de acceso a los servicios financieros afectan paralelamente a las características del servicio, refiriéndose a las dificultades de uso, cómo se vende, y también al control inadecuado por parte de algunos clientes de sus finanzas. En esta línea, Anderloni et al. (2008) resaltan también que esas situaciones que limitan el uso y/o acceso de los productos y servicios financieros adecuados son un obstáculo para dar respuesta a las necesidades de estas personas o colectivos y para que puedan desarrollar una vida normal en la sociedad a la que pertenecen. De manera que incentivar el acceso, se vincula con la mejora en la disponibilidad de los servicios financieros para todas las personas a costes justos, haciendo referencia particularmente a la oferta de servicios; mientras que el uso lo establece la oferta y la demanda y, por tanto, es más medible (World Bank, 2008). Para dejarlo claro, esta institución hace una distinción entre el uso y acceso a los servicios financieros. En la figura 1 se presentan sus elementos. 
Figura. 1. Aspectos diferenciadores entre uso y acceso en el concepto de exclusión financiera

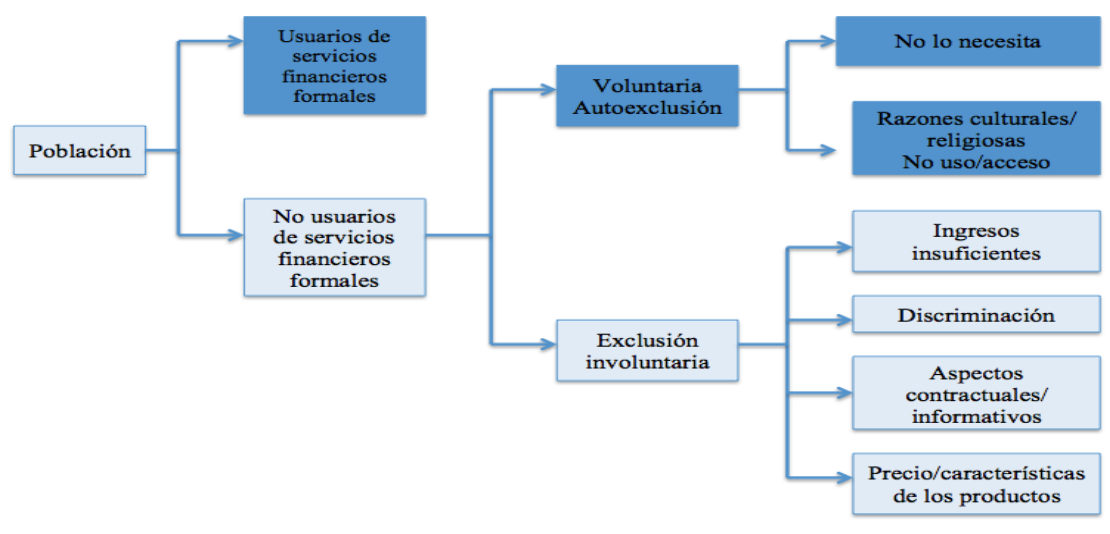

Acceso a servicios financieros
$\square \quad$ Sin acceso a servicios financieros

Fuente: (World Bank, 2008: 43)

El organismo bancario visibiliza algunas situaciones que marcan la diferencia entre el uso o acceso a los servicios financieros y a su vez entre los usuarios y no usuarios. Por un lado, están quienes no los utilizan por razones culturales o religiosas o porque consideran que no los necesitan. En este grupo se encuentran hogares que se inclinan por negociar con dinero efectivo o empresas que no cuentan con proyectos futuros de inversión. Para ser más específicos, estas personas o grupos deciden no hacer uso del sistema, pero posiblemente sí tendrían acceso. También puede ser por el desconocimiento de algunas personas de los servicios y productos financieros, dado que a estas instituciones no les interesa darse a conocer a ciertos colectivos o por la ausencia de educación financiera. Dicho de otro modo, algunas personas pueden tener acceso pero deciden no usar los servicios financieros disponibles mientras que algunos colectivos no pueden acceder porque las características del producto o servicio no se ajusta a sus necesidades o precio, que puede llegar a ser muy elevado para grupos vulnerables de la población. Algunos están representados en hogares o empresas considerados poco fiables debido a su bajo nivel de ingresos o alto riesgo crediticio. Y también por aspectos sociales, religiosos, étnicos o porque viven en territorios considerados por el banco como poco viables comercialmente (World Bank, 2008).

En cuanto a la búsqueda de un concepto consensuado de exclusión financiera, la Unión Europea la define como "...el proceso mediante el cual las personas se encuentran con dificultades de acceso y/o uso de los servicios y productos financieros adecuados a sus necesidades y que les permitan llevar una vida social normal en la sociedad a la que pertenecen" (Kempson et al., 2008: 9). No obstante "Es importante reconocer que la exclusión financiera no es un concepto absoluto (excluido o no) sino relativo, más bien como la pobreza, con grados de exclusión. Las personas varían en su grado de compromiso con el uso de servicios específicos; por ejemplo, la banca de transacciones donde tenemos tanto a los no bancarizados como a los marginados. Y también varían en la cantidad de tipos de productos financieros a los que pueden acceder. Puede ser útil en este contexto utilizar el término financieramente excluido para aquellos que carecen de todos los productos y marginalmente incluido para aquellos que tienen acceso limitado, tal como la pobreza a menudo se describe en términos de estar en el decil o quintil de ingresos más bajos o, alternativamente, de estar por debajo de un umbral, como puede ser el 60\% del ingreso medio (Anderloni et al., 2008:16).

También se puede apuntar como factor que contribuye a las dificultades de acceso al sistema financiero, a la oferta y la demanda de los productos y servicios. Algunas personas no bancarizadas están en esta situación, dado que no se les ha permitido abrir una cuenta. Es el caso de consumidores a los que se les ha negado el acceso porque no cumplen determinadas condiciones, muchas de ellas derivadas de requisitos legales como controles de identidad, el estado de residencia, prueba de ingresos, rentabilidad, evaluación de riesgos, historial de crédito, etc. (Anderloni y Carluccio, 2007). Pero más allá de las limitaciones que sufren algunos de estos grupos en el acceso a los servicios bancarios, en la exclusión financiera se presentan también condicionantes de tipo estructural que dan lugar a un aumento de la vulnerabilidad. En ese sentido, la liberalización de los mercados de servicios financieros es posiblemente la causa más importante de exclusión financiera, junto con la desigualdad de ingresos, cambios estructurales en el mercado laboral, la evolución demográfica o el contexto normativo en cada país (de la Cruz-Ayuso, 2016). 
Por su parte, Anderloni et al. (2008) proponen clasificar los factores de uso y acceso que inciden en la exclusión financiera en tres grupos: 1) factores sociales, 2) factores de oferta y 3) factores de demanda. En la figura 2 se desarrolla cada uno de ellos ${ }^{4}$.

Figura. 2. Factores de acceso o uso que afectan la exclusión financiera

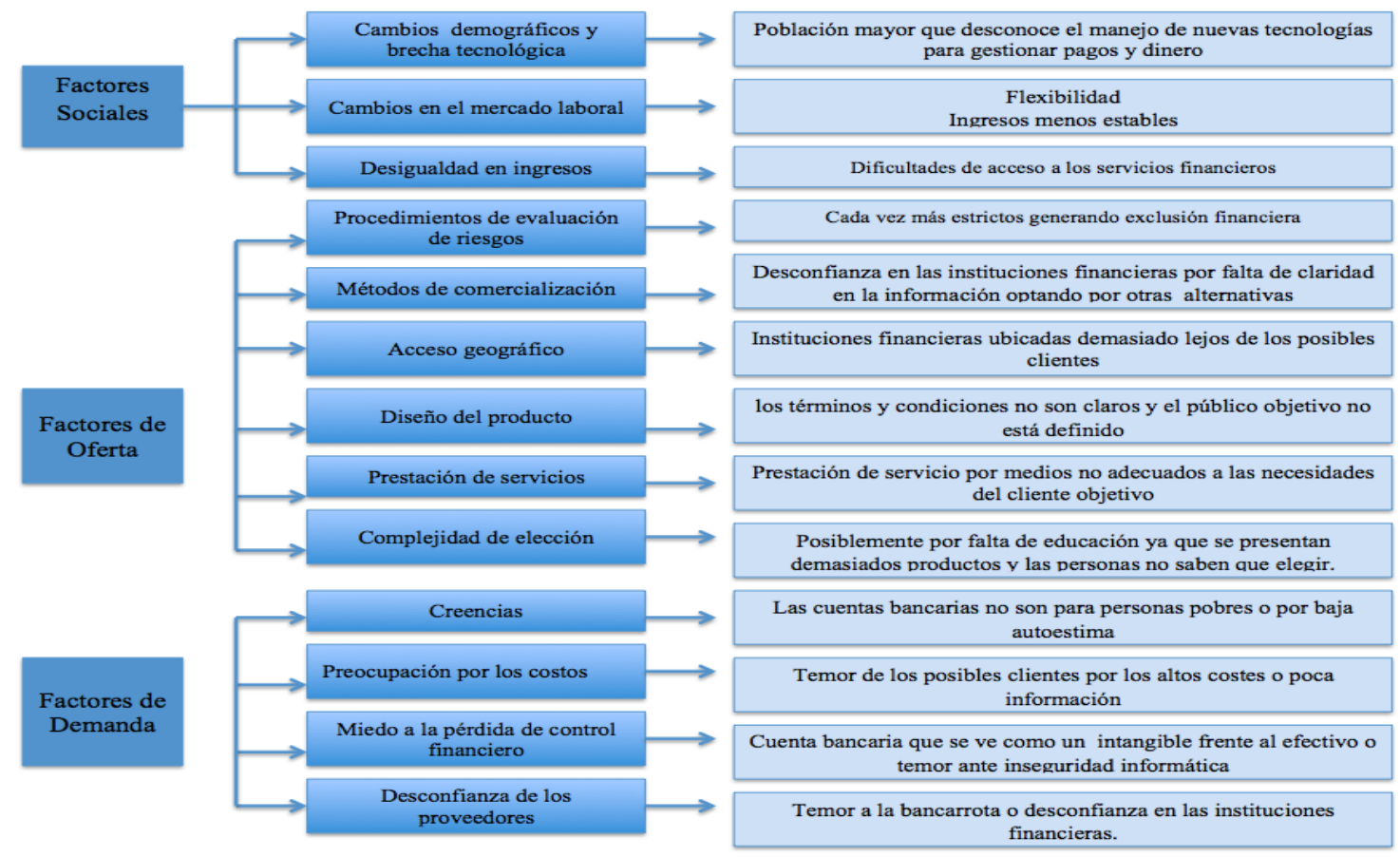

Fuente: elaboración propia a partir de Anderloni et al. (2008)

Por su parte, Zubeldia et al. (2008) amplían la lista de causas y se enfocan en algunos aspectos que tienen que ver con las políticas internas de las entidades bancarias, destacando la insuficiencia de ingresos para los bancos, los escasos movimientos en la cuenta, el saldo negativo durante un plazo demasiado largo, otras deudas del cliente, no contar con un domicilio oficial o fijo, malas relaciones con la entidad, no tener los ingresos domiciliados, el rechazo del cliente a la aplicación de costes en las operaciones por considerados demasiado altos y la dificultad o rechazo del cliente de llevar a cabo sus operaciones en ventanilla electrónica o por teléfono.

Otro factor determinante es el aislamiento geográfico, que se refiere al caso de estar ubicado en territorios en los que no existen sucursales bancarias o no hay acceso a las nuevas tecnologías (Fernández-Olit, 2020). Asimismo, pueden influir criterios subjetivos, refiriéndose a cuando las instituciones financieras optan por limitar el acceso de los solicitantes por razones de tipo personal como edad, discapacidad, situación laboral, nivel de renta, historial financiero, etc. (Llorente San Segundo, 2019).

La crisis económica iniciada en el año 2008 también ha sido considerada como causante de la exclusión financiera. Se puede destacar el caso particular de la crisis inmobiliaria, ligada como causa y efecto de esta crisis bancaria y económica: "La crisis inmobiliaria ha provocado consecuencias de gran calado en la economía española y en particular en su sistema bancario. Por una parte, se ha producido un elevado aumento del desempleo debido a dos elementos principalmente: 1) el cierre de las empresas inmobiliarias y de la construcción, con el consiguiente despido de sus trabajadores; y 2) las fusiones operadas en las entidades bancarias para ajustar sus balances como consecuencia de sus activos tóxicos (procedentes del sector inmobiliario principalmente)" (Sanchis, 2013: 67). Por lo cual, se produce una disminución en la rentabilidad dada la contracción del crédito; una disminución de la liquidez como consecuencia de las pérdidas producidas por los créditos incobrables; y, por último, un incremento desproporcionado en el cobro de comisiones bancarias para intentar equilibrar la pérdida en los márgenes de utilidad en el negocio bancario. En respuesta a este desmedido interés en la ganancia por parte de los bancos, se ha podido generar un incremento de la exclusión financiera, particularmente entre los clientes con menores recursos (Belmonte et al., 2013). La actual crisis provocada por el Covid-19 está incrementando los niveles de pobreza y de

4 En los informes presentados por cada país, los factores sociales han sido mencionados mayoritariamente como la causa de la exclusión financiera; no obstante, también se presentan características de oferta y demanda que denotan fallos importantes. Se puede inferir que existen más elementos de los informados, pero que solo se visibilizan en cuanto se explora la situación en detalle y esta evidencia solo existe en una minoría de países. 
exclusión social de la población más vulnerable (Nemecio, 2020), por lo que se va a hacer necesario un aumento en la inclusión financiera, que dependerá del nivel de resiliencia de la banca (Maudos, 2020). Aunque las causas de las dos crisis son muy diferentes (crisis financiera y de confianza en el caso de la de 2008 y crisis sanitaria en el caso de la 2020), las consecuencias son las mismas (mayor exclusión social); si bien se prevé que el impacto de la crisis actual sea mayor.

A los efectos negativos de la crisis ya mencionados, es relevante tener en cuenta también los procesos de fusiones entre entidades de crédito y la transformación de las cajas de ahorros españolas, que antes de la crisis lograron sostener ampliamente la cobertura de las poblaciones más vulnerables (Fernández-Olit, 2012). Si bien el objetivo de esta restructuración fue la eficiencia operativa e institucional, también conllevaba unas consecuencias desde el bienestar que falta evaluar, dado que la disminución en la red de oficinas en los territorios disminuye el acceso a los servicios bancarios a través de canales tradicionales, contrario al fin que tenían las cajas en su concepción, centradas en contribuir a evitar la exclusión financiera de la ciudadanía, reflejándose en la apertura de oficinas en lugares considerados menos rentables (Oliver y Pardo, 2015).

Lo indicado tiene que ver también con la poca presencia bancaria y el consecuente bajo nivel de concesión de crédito en algunos territorios y que pueden determinar la degradación económica del mismo (Albers, 2007). De manera que cuando no se cuenta con sucursales físicas en algunos territorios, especialmente rurales o ubicados en áreas remotas, se puede constituir una barrera para el acceso al sector y, en consecuencia, una exclusión financiera (Gómez-Barroso y Marbán-Flores, 2013). Esta falta de sucursales bancarias se presenta especialmente en las pequeñas comunidades rurales, debido a que la banca los considera territorios de riesgo, por su aparente poca o nula rentabilidad, generando resquebrajamientos territoriales en los países. Es tal la ausencia de entidades de crédito que los autores a manera de analogía la comparan con lo que a mediados del siglo XX geógrafos franceses denominaron "desiertos bancarios"; teniendo en cuenta características importantes como la estrecha competencia y prestación de servicios financieros y como la solicitud de préstamos o algún servicio por una persona, que conlleva el incremento en el riesgo de exclusión (Zubeldia et al., 2008; Carbó y Rodríguez, 2015).

Es de resaltar que el recorte de personal bancario y el cierre de sucursales genera que en muchos territorios solo quede una sucursal y en algunos casos no cuenten con oficinas, por lo que las personas quedan a expensas de una total exclusión financiera. Lo anterior se convierte en un problema, teniendo en cuenta que para estar integrados en sociedades modernas es casi un requisito indispensable poder acceder a los servicios financieros, dada la "financiarización" que se ha hecho con muchas de las actividades que antes no eran requisito, como pago de servicios públicos o salarios, por lo que el buen servicio que puedan ofrecer a las personas en las oficinas bancarias es considerado un medio relevante para favorecer la inclusión financiera (Fernández-Olit, 2016).

Para puntualizar lo anterior, hay que mencionar además que algunos colectivos están más expuestos a las dificultades de acceso a los servicios financieros básicos en función de factores como: 1) el aumento en las dificultades para adquirir una cuenta bancaria sin costes financieros y afectando la posibilidad de ahorrar, realizar operaciones y pagos importantes; 2) la necesidad de estos colectivos de acudir a "prestamistas ilegales", arriesgando incluso hasta la vida; 3) los complicados trámites cuando se tienen la necesidad de adquirir un seguro, dada la cobertura del riesgo; 4) los nuevos canales tecnológicos que exigen cierto desarrollo cultural (banca por Internet y tarjetas); 5) poca oferta de horarios para atención de oficina y de operaciones de ventanilla; y 6) municipios poco poblados (Belmonte et al., 2013).

Lo abordado visibiliza los problemas en especial de estos colectivos en el momento de abrir una cuenta bancaria, por la evaluación financiera y el alto número de documentos exigidos y que se presentan mayoritariamente por procedimientos internos de las entidades financieras a la hora de recoger la información en respuesta a problemas socioeconómicos de los clientes (Zubeldia et al., 2008). Se suma a lo anterior que los bancos no diseñan productos y servicios para todos los grupos de la población, cobrando sobrecostes por mantenimiento que generan limitaciones para el uso y acceso a los servicios y productos financieros por parte de toda la población (De la Orden, 2015). De ahí que la poca oferta y las condiciones que ofrece la banca y que por razones socioeconómicas imposibilitan a la población a acceder a los servicios financieros, desencadena un incremento de la exclusión financiera. En tanto una persona no cuente con una oferta que se acomode a sus ingresos y necesidades y que además le permita cubrir los costes transaccionales, no podrá abrir una cuenta bancaria (Gómez-Barroso y Marbán-Flores, 2013). Se suman a las causas de exclusión financiera los factores socioeconómicos con aspectos asociados a un nivel bajo de renta: ser mujer, desempleado, estudiante o jubilado, así como presentar un determinado nivel de diversidad funcional, familias monoparentales, tener un bajo nivel de estudios, vivir en una zona de baja densidad de población, ser inmigrante, etc. (Zubeldia et al, 2012).

Coincide Barr (2004) cuando se refiere a los bajos ingresos de algunos hogares como causante del poco acceso de grupos vulnerables al sistema financiero, sumándose a los altos costes transaccionales en servicios básicos formales o de los cambistas y los otros proveedores alternativos de servicios financieros a los cuales terminan acudiendo. Por tanto, para estas familias resulta más difícil ahorrar y planificarse financieramente para su futuro, comprar una casa, enviar a sus hijos a la universidad o hacer inversiones e incluso cualquier 
gasto extra como una urgencia médica o laboral dado que los deja más vulnerables. De ahí que los grupos o colectivos que tienen mayor riesgo de sufrir exclusión financiera sean quienes cuentan con menores ingresos, los migrantes, personas con alguna diferencia funcional que en ocasiones no pueden trabajar, quienes viven en zonas rurales, personas que no cuentan con una adecuada cultura financiera o quienes en muchas ocasiones no tienen acceso a la tecnología. "La exclusión financiera se ha sumado, de esta manera, a los ejes de la vulnerabilidad a la que se enfrentan aquellos que no tienen servicios esenciales de calidad, tales como el empleo, la vivienda, la educación o la asistencia sanitaria" (De la Cruz-Ayuso, 2016: 92).

En esta línea, Joassart-Marcelli y Stephens (2009) resaltan como factores que afectan al acceso a la banca los aspectos individuales como son la educación, los ingresos, el estatus legal y la lengua. Además, no se puede ignorar, como se ha hecho en reiteradas ocasiones, que los colectivos sociales pobres, minoritarios o inmigrantes son excluidos no solo por su condición, sino también a partir de la ubicación geográfica de las sucursales bancarias y la limitación que generan para acceder al sistema financiero, ya que muchos están inmersos en territorios completamente desfavorecidos, generando prácticas financieras informales. Fernández-Olit et al. (2018) ponen el foco también en la vulnerabilidad, entendida ésta como esos aspectos de tipo individual, obstáculos y limitaciones estructurales que no permiten lograr un valor apropiado en las transacciones del consumidor y, por tanto, inciden en la exclusión financiera.

A modo de síntesis, en la tabla 1 se recogen las principales causas de vulnerabilidad financiera analizadas en los párrafos anteriores.

Tabla. 1. Causas de la vulnerabilidad financiera

\begin{tabular}{|c|c|}
\hline CAUSA & AUTORES \\
\hline $\begin{array}{l}\text { El analfabetismo y la falta de cultura financiera puede disminuir la confianza y la } \\
\text { capacidad de actuar socialmente cuando se niegan o amenazan las necesidades del } \\
\text { consumidor. }\end{array}$ & $\begin{array}{l}\text { Adkins y Ozanne }(2005), \\
\text { Joassart-Marcelli y Stephens } \\
\text { (2009) y De la Cruz-Ayuso, } \\
(2016)\end{array}$ \\
\hline Ausencia de control del usuario y abuso por parte de las instituciones financieras. & $\begin{array}{l}\text { Albers (2007), De Meza et al. } \\
\text { (2008) y Fernández-Olit (2012) }\end{array}$ \\
\hline $\begin{array}{l}\text { No contar con ingresos suficientes, autoexclusión y la disponibilidad de cuentas de } \\
\text { familiares o amigos para pagar los gastos. }\end{array}$ & $\begin{array}{l}\text { Joassart-Marcelli y Stephens } \\
\text { (2009), Zubeldia et al. }(2012) \text { e } \\
\text { Ipsos (2013) }\end{array}$ \\
\hline $\begin{array}{l}\text { El acceso tecnológico limitado de los consumidores vulnerables y su desinterés en el } \\
\text { uso de la banca electrónica. }\end{array}$ & $\begin{array}{l}\text { Ipsos (2013), Fernández-Olit } \\
\text { (2012) y Fernández-Olit (2016) }\end{array}$ \\
\hline $\begin{array}{l}\text { Malas prácticas comerciales, como el marketing confuso, que dificulta la } \\
\text { comparación de productos de diferentes entidades e induce la toma de decisiones } \\
\text { instantáneas. }\end{array}$ & $\begin{array}{l}\text { Bowman et al. (2014) y De la } \\
\text { Orden (2015) }\end{array}$ \\
\hline $\begin{array}{l}\text { Los consumidores experimentan un riesgo de vulnerabilidad, es decir, valor } \\
\text { inapropiado en las transacciones de los consumidores en función de cuatro factores: } \\
\text { individual (capacidades o estado socioeconómico), familia (estructura y roles } \\
\text { familiares), comunidad (lugar de residencia o acceso limitado a bienes y servicios) y } \\
\text { macro fuerzas (regulación o acceso a la tecnología). }\end{array}$ & $\begin{array}{l}\text { Baker y Mason (2012) y } \\
\text { Fernández-Olit et al. (2018) }\end{array}$ \\
\hline $\begin{array}{l}\text { Los hogares con bajos ingresos, desempleados o con poca educación son los más } \\
\text { propensos a verse afectados por la banca. }\end{array}$ & $\begin{array}{l}\text { Ampudia y Ehrmann (2016) y } \\
\text { Barr (2004) }\end{array}$ \\
\hline $\begin{array}{l}\text { La calidad del entorno institucional, el coste de hacer cumplir los contratos y el grado } \\
\text { de propiedad gubernamental de los bancos como determinantes de la banca. }\end{array}$ & $\begin{array}{l}\text { Beck et al. }(2007,2009) \text {, } \\
\text { Belmonte et al. (2013) y } \\
\text { Gómez-Barroso y Marbán- } \\
\text { Flores (2013) }\end{array}$ \\
\hline $\begin{array}{l}\text { Inseguridad laboral: personas desempleadas o que trabajan en la economía informal y } \\
\text { bajos ingresos }\end{array}$ & $\begin{array}{l}\text { Ampudia y Ehrmann (2016) y } \\
\text { Anderloni et al. (2008) }\end{array}$ \\
\hline Población inmigrante en España. & Anderloni y Carluccio (2007) \\
\hline
\end{tabular}

Fuente: elaboración propia con base en Fernández-Olit et al. (2018) 
Por tanto, se puede resumir señalando que la exclusión financiera afecta a personas y colectivos que se encuentran especialmente en condición de vulnerabilidad, con unas situaciones socioeconómicas similares, aunque en niveles independientes de exclusión de acuerdo a lo que prevalece en cada país: personas con bajos ingresos, desempleados, solteros, familias monoparentales, personas que no pueden trabajar por enfermedad o discapacidad, jóvenes y jubilados, así como las minorías étnicas e inmigrantes (Kempson et al., 2007).

En referencia a la inclusión financiera, se percibe de diferentes maneras teniendo en cuenta su contexto. Desde un perspectiva más simple, se considera que sólo el acceso al crédito es inclusión financiera; sin embargo, desde otros puntos de vista más amplios, se incluye todos los servicios prestados por las instituciones financieras: además de las necesidades de inversión personal y privada de individuos y grupos, los requisitos de inversión pública universal necesarios para el desarrollo de la infraestructura, los servicios de sectores sociales, servicios públicos y las fuerzas productivas para la creación de capacidades y recursos, etc. Por lo tanto, la inclusión financiera puede hacer referencia a diferentes concepciones, más o menos amplias, del dinero y las finanzas, pero siempre con el objetivo último de abolir directamente el estado de exclusión social en la economía (Rangarajan Commitee, 2008).

No obstante, la inclusión financiera se asocia también con costes financieros más bajos, mayor proximidad a los intermediarios financieros, derechos legales y ambientes más políticamente estables (Allen et al., 2016). De ahí que sea presentada como un proceso que asegura oferta de servicios y créditos adecuados, oportunos y con precios asequibles para grupos vulnerables, desfavorecidos y de bajos ingresos de la sociedad (Marimuthu y Mathan, 2015). Sanchis (2016: 68) manifiesta que "la inclusión financiera se puede entender como un proceso a través del cual se persigue que las familias y las empresas puedan tener acceso y uso efectivo de los servicios financieros necesarios a través de un sistema regulatorio que favorezca la responsabilidad y la sostenibilidad. Por tanto, lo que se busca es incluir a la población no bancarizada en los sistemas financieros formales con el fin de darles la oportunidad de acceder a los servicios financieros formales básicos necesarios, principalmente ahorro, pagos, transferencias, créditos y seguros". Coinciden Dixit y Ghosh (2013) en referencia a esa prestación de servicios bancarios y de crédito a bajos costes en beneficio especialmente de colectivos vulnerables que al final suelen ser los grupos desfavorecidos o excluidos. Estos servicios incluyen servicios de ahorro, préstamos, seguros, pagos y remesas ofrecidos por el sistema financiero. Los bajos costes incluyen, por ejemplo, bajas tasas de interés que den lugar a incrementar de manera significativa el acceso a estos servicios, no queriendo decir que todas las personas o colectivos pueden endeudarse de manera ilimitada o más allá de sus posibilidades (World Bank, 2008).

Sarma y Pais (2011) señalan que esta inclusión tiene que ver con un proceso que implica la facilidad de acceso, uso y disponibilidad de los servicios bancarios para todos los miembros de una economía y que facilita el uso eficiente de los recursos productivos y, por tanto, reduce potencialmente el coste del capital. Arora (2018) suma a lo anterior la calidad en los productos y servicios financieros como elemento que refleja su utilidad acorde a las necesidades de los clientes. Yangdol y Sarma (2019), por su parte, reiteran que la inclusión financiera deja ver la capacidad de personas o colectivos para acceder o usar de manera sencilla a los sistemas financieros formales. En este sentido, Llorente San Segundo (2019) visibiliza un riesgo asociado a esta falta de acceso, refiriéndose a situaciones de inseguridad que se presentan cuando estos colectivos muestran mayores dificultades financieras y acceden a ofertas de financiación alternativas o informales y no logran devolver sus préstamos. Los prestamistas pueden utilizar métodos de cobro incluso violentos e intimidantes, lo que quiere decir que esta falta de acceso a los sistemas de crédito causa grandes consecuencias sociales.

Dicho lo anterior, y con el fin de aportar otros conceptos de inclusión social, desde la perspectiva de instituciones gubernamentales, bancarias o de organizaciones no gubernamentales, en la tabla 2 se recogen algunos de los conceptos analizados. 
Tabla. 2. Conceptos institucionales de la inclusión financiera

\begin{tabular}{|l|l|}
\hline \multicolumn{1}{|c|}{ CONCEPTO } & INSTITUCIÓN \\
\hline $\begin{array}{l}\text { Utilización de servicios financieros por parte de personas y empresas. Es un } \\
\text { concepto multidimensional que refleja la variedad de servicios financieros desde } \\
\text { pagos y cuentas de ahorro, hasta créditos, seguros, pensiones y mercados de } \\
\text { valores. }\end{array}$ & World Bank (2014) \\
\hline $\begin{array}{l}\text { Acceso oportuno y adecuado de productos y servicios financieros regulados y } \\
\text { propendiendo por su uso para toda la sociedad a partir de la inclusión e } \\
\text { implementación de la educación financiera generando bienestar financiero e } \\
\text { inclusión económica y social. }\end{array}$ & OCDE/INFE (2013) \\
\hline $\begin{array}{l}\text { Acceso efectivo de personas en edad productiva servicios financieros provistos por } \\
\text { las instituciones formales: créditos, cuentas de ahorro, pagos y seguros. A partir de } \\
\text { la prestación de servicios que den respuesta a las necesidades de sus clientes, con } \\
\text { costes adecuados y sostenible para el que lo provee. }\end{array}$ & GPFI/CPAF (2011) \\
\hline $\begin{array}{l}\text { Proceso que garantiza el acceso a los servicios financieros y el crédito oportuno y } \\
\text { adecuado para personas o colectivos vulnerables, es decir para grupos de bajos } \\
\text { ingresos a un coste asequible. }\end{array}$ & $\begin{array}{l}\text { Rangarajan } \\
\text { Commitee (2008) }\end{array}$ \\
\hline
\end{tabular}

Fuente: elaboración propia a partir de las referencias utilizadas.

Todo esto permite visibilizar que la inclusión financiera es una condición necesaria para la reducción de la pobreza, teniendo en cuenta que otorga a los segmentos más pobres de la población la posibilidad de incrementar o estabilizar sus ingresos, y los provee de una mayor resistencia a los choques económicos y de la oportunidad de poseer activos. También contribuye al desarrollo del sector financiero, lo que incentiva el crecimiento económico mediante la movilización de ahorro y la inversión en el crecimiento del sector productivo, favoreciendo indirectamente la disminución de la pobreza (G-20,2012). Se resalta, además, que la inclusión financiera ayuda a construir el ahorro interno, fortalecer la resiliencia de los hogares, del sector doméstico y estimula la actividad financiera y empresarial; de ahí que se considere necesario establecer los efectos que tiene la inclusión financiera a nivel social.

En consecuencia, los mercados financieros incluyentes y eficientes pueden mejorar las condiciones de vida de las personas, reducir los costes transaccionales, impulsar la actividad económica y mejorar la prestación de servicios con beneficios sociales; incluso resaltan la correlación positiva entre la inclusión financiera, el crecimiento y el empleo (Cull et al., 2014).

\subsection{Exclusión / Inclusión Social}

La exclusión social como discurso se origina en Francia en los años setenta del pasado siglo, para iniciar su expansión posterior hacia otros países europeos. La Unión Europea, por su parte, empieza a referirse a esta exclusión en la siguiente década. Más allá del origen de términos que se tenga en cuenta para definirla, lo que es cierto es que se establece una relación condicionante con la pobreza, desde la privación, refiriéndose a que algunas personas, familias o colectivos carecen de recursos para participar activamente en la sociedad a la que pertenecen. Según Gordon (1998), desde la investigación teórica se ha buscado diferenciar entre los términos de pobreza y de exclusión social. Es así como en algunas instancias, la pobreza se establece como un concepto un tanto limitado que se enfoca a situaciones directamente relacionadas con los recursos económicos; mientras que la exclusión social se dedica a situaciones vinculadas con la integración de los individuos en la sociedad. De hecho, durante los años noventa del Siglo XX, la Unión Europea aborda la exclusión social desde el desempleo o la exclusión del trabajo remunerado (Gordon, 1998).

En lo que se refiere al origen francés del término durante la década de los setenta del Siglo XX, Levitas (1998: 41) destaca la falta de consenso en cuanto a su significado, manifestando que "no existe una definición universalmente aceptada ni teórica ni operativamente". Sin embargo, lo que queda claro es que cuando se habla de pobreza, al tratarse de recursos económicos, se hace referencia a lo que las personas (no) pueden acceder, en tanto que la exclusión social está vinculada especialmente con lo que las personas o colectivos (no) están habilitados para hacer.

Posteriormente, Hernández (2008: 39) define la exclusión social como un "un conjunto de procesos más que una situación estable. No afecta a grupos predeterminados concretos, sino que afecta de modo cambiante a grupos y personas en función de su ecuación de vulnerabilidad respecto a las dinámicas sociales de riesgo y marginación. Las fronteras de la exclusión son móviles y cambiantes en un marco de cambio tecnológico 
acelerado: riesgo de ruptura familiar, riesgo de precariedad laboral, riesgo de descualificación, riesgo de dependencia física, entre otros". Estos procesos tienen como punto común la pobreza como su causa, requiriendo añadir condiciones adicionales como edad, género, raza, sexo, entre otras cuestiones que conllevan a ubicar a los individuos o colectivos fuera de la redes o tejidos sociales, afectando el desarrollo y limitando el avance social de los colectivos, la participación y las posibilidades de desarrollo (Nieto-Morales, 2012). Por su parte, Loisy (2000) se refiere a la exclusión social como una situación permanente en condición de pobreza con pocas posibilidades de transitar a la inclusión o a un estado de mayor bienestar. Dado que no incide en el colectivo social en cuanto a condiciones de vida o consumo generales, también se debe tener en cuenta el contexto o condiciones particulares de cada persona.

Por tanto, la exclusión social se sitúa como un proceso dinámico y en aumento, que influye en diferentes personas y está asociado a una acumulación de factores que se interrelacionan y retroalimentan entre sí (Toset, 2009). Asimismo, abarca varios ámbitos de la realidad social, de tipo económico, estructural y sociocultural (Fabre, 2000). Dicho de otra manera, es un proceso de distanciamiento cada vez más profundo entre algunos colectivos y la integración social, en el que pueden presentarse niveles en cuanto a su intensidad: desde la precariedad o vulnerabilidad mínima a fenómenos de exclusión más fuertes y, por tanto, progresivos (Subirats, Alfama y Pineda, 2009). En este sentido, se puede decir que se encuentra vinculada a elementos, situaciones y determinantes del sistema social y económico que inciden progresivamente en diversos sectores de la sociedad, reflejándose especialmente en los entornos económico-financiero, laboral, formativo, socio-sanitario, residencial, relacional, de ciudadanía y participación (Fuertes y Chowdhury, 2009). De ahí que se tenga muy en cuenta el contexto social en el que se da la exclusión, dando lugar a que la exclusión social sea "una construcción social, determinada por la respuesta de todos los agentes de la sociedad y vinculada con la posición particular en la estructura social. En suma, la exclusión social es el resultado de una determinada estructura social, política, cultural y económica. Por tanto, es relativa, depende del contexto" (Hernández, 2008: 39).

Por su parte, Tezanos (2001) la presenta como un concepto en negativo, es decir, desde la carencia, desde lo que no se tiene. Dejando ver que para entenderlo se debe tener en cuenta el referente opuesto, en este caso la integración. De hecho, existe una relación entre carencia y desigualdad de las personas a la hora de acceder a los derechos sociales y la situación de exclusión social. Sin embargo, la deja ver como multidimensional y multifactorial, lo que complica su conceptualización; y deja claro que no es un estado, sino más bien un proceso (Hernández, 2008).

Sinclair (2001: 14) señala que la exclusión social está vinculada con aspectos referidos a privaciones interrelacionadas que disminuye a personas, familias o comunidades las oportunidades para ser parte en la vida social. El autor cita a Bradshaw et al. (1998), donde se recoge una encuesta de pobreza y exclusión social, y se distingue cuatro dimensiones principales de exclusión: 1) Empobrecimiento o exclusión de ingresos y recursos adecuados; 2) Exclusión del mercado laboral, que está vinculada al desempleo y la inactividad económica involuntaria; 3) Exclusión del servicio, donde se incluye la exclusión financiera; y 4) Exclusión de relaciones sociales, vinculada al aislamiento social y ausencia de participación en actividades socialmente necesarias.

En línea con lo anterior, es relevante también añadir algunas situaciones y factores que inciden en los niveles de vulnerabilidad y exclusión. Así, el género puede ser un factor determinante, ya que las mujeres son las más propensas a quedar excluidas, incluso por temas culturales, dado que en algunas tradiciones están apartadas de la vida laboral, no contando con acceso a formación en igualdad de condiciones. La edad también es un factor destacado, dado que la exclusión afecta especialmente a los jóvenes y los mayores. Del mismo modo que la etnia o el origen con la exclusión en las personas que no tienen regularizados sus documentos y tienden a vivir sin las garantías de sus derechos fundamentales (Fuertes y Chowdhury, 2009). En relación a esta última premisa, Arroyo (2013) suma otros factores desencadenantes de la exclusión social: altas tasas de desempleo y precarización en las condiciones de trabajo, débil acceso a las redes de protección familiar y procesos migratorios no regulados con personas que no cuentan con los documentos exigidos y que al final acaban siendo colectivos desprotegidos y en condiciones de marginalidad. De ahí que cuando se hable de exclusión social necesariamente se ha de hablar del orden social (del debe ser), que se relaciona en definitiva con el devenir social (Tezanos, 2001). De igual manera, se deben tener en cuenta otro tipo de desigualdades, como las que surgen a partir de brechas sociales o la ruptura de los lineamientos más fundamentales de la integración como ser parte del mercado productivo, la participación política, el reconocimiento social o pertenecer a una comunidad (Toset, 2009: 50). Dicho de otro modo, la exclusión social va de la mano no solo de los recursos económicos, como es el caso de la pobreza, sino también de la negación de la ciudadanía, es decir, la privación de los derechos y libertades básicas de los individuos. En este sentido, la exclusión social se refiere a la separación del individuo de los espacios sociopolíticos, económicos y culturales (Arroyo, 2013).

A su vez, Chuaqui et al. (2016: 164) reconocen algunos niveles de exclusión social: 1) De ingreso: dificultad para ingresar en cualquier sistema social, por razones de tipo económico, religioso, de ideología y género, entre otras; 2) De acceso: a los servicios o derechos fundamentales, como la salud, la educación, la 
cultura, etc.; y 3) Relacional: dificultad para mantener relaciones sociales o permanecer en un mismo sistema, grupo por discriminación y la estigmatización. También se han incluido otras dimensiones y colectivos al proceso de exclusión social, como fenómenos naturales, conflictos bélicos o los procesos migratorios, de manera que amplía los rangos al tener en cuenta las desigualdades sociales (Fuertes y Chowdhury, 2009). Por consiguiente, la exclusión social incide directamente en la calidad de vida de los individuos y su relación con el conjunto de la sociedad. Asimismo, involucra aspectos como la falta de recursos, derechos, bienes y servicios, la imposibilidad de participar en las relaciones y actividades normales, de las que sí pueden hacerlo la mayoría de las personas en una sociedad, ya sea en el ámbito económico, social, cultural o político (Levitas et al., 2007).

La Tabla 3 resume las causas más destacadas de la exclusión social a partir de los trabajos analizados anteriormente.

Tabla. 3. Causas de la exclusión social

\begin{tabular}{|c|c|}
\hline CAUSA & AUTORES \\
\hline La pobreza como causa principal de la exclusión social & $\begin{array}{l}\text { Gordon (1998) y Hernández } \\
\text { (2008) }\end{array}$ \\
\hline Condiciones adicionales como edad, género, raza, sexo, etc. & $\begin{array}{l}\text { Hernández (2008), Nieto- } \\
\text { Morales (2012) y Fuertes y } \\
\text { Chowdhury (2009) }\end{array}$ \\
\hline El contexto o condiciones particulares de cada persona. & $\begin{array}{l}\text { Loisy (2000), Chuaqui et al. } \\
\text { (2016) y Levitas et al. (2007) }\end{array}$ \\
\hline $\begin{array}{l}\text { Se encuentra vinculada a elementos, situaciones y determinantes del sistema social } \\
\text { y económico que inciden progresivamente en diversos sectores de la sociedad. Es } \\
\text { el resultado de una determinada estructura social, política, cultural y económica. }\end{array}$ & $\begin{array}{l}\text { Fabre (2000), Toset (2009), } \\
\text { Subirats, Alfama y Pineda } \\
\text { (2009) y Fuertes y } \\
\text { Chowdhury (2009) }\end{array}$ \\
\hline $\begin{array}{l}\text { Está vinculada con aspectos referidos a privaciones interrelacionadas que } \\
\text { disminuye a personas, familias o comunidades las oportunidades para ser parte en } \\
\text { la vida social. }\end{array}$ & Sinclair (2001) \\
\hline $\begin{array}{l}\text { Altas tasas de desempleo y precarización en las condiciones de trabajo, débil } \\
\text { acceso a las redes de protección familiar y procesos migratorios no regulados. }\end{array}$ & $\begin{array}{l}\text { Arroyo (2013) y Fuertes y } \\
\text { Chowdhury (2009) }\end{array}$ \\
\hline $\begin{array}{l}\text { A partir de brechas sociales o la ruptura de los lineamientos más fundamentales de } \\
\text { la integración como ser parte del mercado productivo, la participación política, el } \\
\text { reconocimiento social o pertenecer a una comunidad. }\end{array}$ & Toset (2009) y Arroyo (2013) \\
\hline
\end{tabular}

Fuente: elaboración propia con base en los diferentes trabajos referenciados

Para dar cierre a este recorrido teórico, se concluye que el concepto de inclusión social presenta una fuerte ambigüedad, de manera que no se logra hacer una clara diferenciación entre los elementos que la componen y otros procesos relacionados con la cohesión o integración social y tampoco se logra identificar sus dimensiones, sus características y un concepto central único como tal (Álvarez, 2016). Por tanto, más que un concepto, la inclusión social representa una obligación desde lo político, un mandato que implanta la necesidad de evaluar el progreso de las sociedades hacia la reducción de la pobreza y de la exclusión social (United Nations, 2010) y para ello recurren a indicadores que permiten determinar el grado de pobreza y exclusión social, definir la dirección de los cambios en el tiempo y medir cómo afectan las medidas desarrolladas a la promoción de la inclusión social. Con el objeto de hacer una delimitación del concepto, se suman en la tabla 4 algunas definiciones planteadas por instituciones relacionadas con el desarrollo. 
Tabla. 4. Conceptos de Inclusión social de otras instituciones del desarrollo.

\begin{tabular}{|c|c|}
\hline CONCEPTO & INSTITUCIÓN \\
\hline $\begin{array}{l}\text { Proceso por el cual se alcanza la igualdad, y como un proceso para cerrar las brechas } \\
\text { en cuanto a la productividad, a las capacidades (educación) y el empleo, la } \\
\text { segmentación laboral, y la informalidad, que resultan ser las principales causas de la } \\
\text { inequidad. }\end{array}$ & CEPAL (2015) \\
\hline $\begin{array}{l}\text { Así como de mejorar la habilidad, la oportunidad y la dignidad de las personas que se } \\
\text { encuentran en desventaja debido a su identidad, para que puedan participar en la } \\
\text { sociedad. }\end{array}$ & World Bank (2013) \\
\hline $\begin{array}{l}\text { Una sociedad inclusiva es aquella que se eleva por encima de las diferencias de raza, } \\
\text { género, clase, generación y geografía para garantizar la igualdad de oportunidades sin } \\
\text { importar el origen, y una que subordina el poder militar y económico a la autoridad } \\
\text { civil. En una sociedad inclusiva, la interacción social se rige por un conjunto acordado } \\
\text { de instituciones sociales. La capacidad de todos los ciudadanos para determinar cómo } \\
\text { funcionan esas instituciones es de hecho un sello distintivo de una sociedad inclusiva. }\end{array}$ & $\begin{array}{l}\text { United } \\
(2010)\end{array}$ \\
\hline $\begin{array}{l}\text { Proceso que garantiza que las personas en riesgo de pobreza y exclusión obtengan las } \\
\text { oportunidades y los recursos necesarios para participar plenamente en vida económica, } \\
\text { social y cultural. Además de disfrutar de un nivel de vida y bienestar. }\end{array}$ & World Bank (2007) \\
\hline $\begin{array}{l}\text { La inclusión es parte de un proceso más amplio de cohesión social, junto con otras tres } \\
\text { grandes dimensiones: la participación de individuos en la vida social, la percepción de } \\
\text { satisfacción con sus actividades cotidianas y la tensión social. En esta definición, la } \\
\text { inclusión social supone aspectos que potenciarían el bienestar social de cada individuo, } \\
\text { en oposición a la exclusión social, la pobreza y la desigualdad. }\end{array}$ & OCDE 2007 \\
\hline $\begin{array}{l}\text { Proceso que garantiza que las personas en riesgo de pobreza y exclusión social } \\
\text { obtengan las oportunidades y los recursos necesarios para participar plenamente en la } \\
\text { vida económica, social y cultural, y para disfrutar de un nivel de vida y bienestar que se } \\
\text { considera normal en el mundo, en la sociedad en la que viven. Asegura que tengan una } \\
\text { mayor participación en la toma de decisiones que afecta sus vidas y el acceso a sus } \\
\text { derechos fundamentales. }\end{array}$ & $\begin{array}{l}\text { European } \\
\text { Commission (2004) }\end{array}$ \\
\hline
\end{tabular}

Fuente: elaboración propia con base en conceptos propuestos por organismos multilaterales.

A modo de síntesis, Hernández (2008) propone una definición de inclusión social, identificándola como un proceso que permite a personas o colectivos vulnerables tener mejores condiciones de vida al acceder a los recursos a los que tienen derecho, de tal manera que logren vivir en condiciones óptimas en aspectos básicos como los económicos, sociales y culturales, ejercer su participación como ciudadanos y acceder a sus derechos fundamentales.

\section{Relación conceptual causa-efecto entre la inclusión/exclusión social y financiera: análisis bibliométrico}

Para analizar la relación causa-efecto entre la inclusión/exclusión social y la inclusión/exclusión financiera se ha realizado un análisis bibliométrico. Con él se han identificado los principales trabajos publicados sobre el tema durante el período 2000-2020. La revisión de la literatura se ha realizado siguiendo 5 etapas metodológicas (Tranfield et al., 2003; Petticrew i Roberts, 2006; Johnson y Schaltegger, 2016): 1) identificación de las palabras clave y creación de cadenas de búsqueda basadas en las palabras clave identificadas; 2) selección de los estudios relevantes de investigación a través de una base de datos; 3) análisis de los documentos identificados basado en criterios de inclusión y exclusión; 4) extracción de datos 
a partir de la base de datos utilizada (en nuestro caso Excel); y 5) síntesis de los datos e informe final. La cadena de búsqueda que se ha seleccionado es "social inclusion and financial inclusion" y "social exclusion and financial exclusion". La base de datos que se ha utilizado para la búsqueda ha sido la Web of Science, aunque se ha completado con la búsqueda en Google Scholar, para incluir todas aquellas revistas que no están incluidas en la primera (Johnson y Schaltegger, 2016). Con el objeto de reducir la gran cantidad de literatura disponible, se han establecido unos criterios de inclusión y de exclusión, basándonos en el proceso de revisión sistemática recogido en otros trabajos (Moustaghfir, 2008; Johnson y Schaltegger, 2016). Se han excluido de la búsqueda los trabajos correspondientes a conference papers, working papers, technical reports y practical handbooks. En cambio, sí se han incluido en la búsqueda los artículos académicos revisados por pares (artículos científicos de revistas con evaluadores externos).

La búsqueda inicial de documentos a través de las cadenas de cerca en la Web of Science ha dado como resultado 42 documentos, incluidos dentro del dominio de investigación en Social Science. Se han examinado y relacionado los títulos y los abstracts de los artículos con los criterios de inclusión y de exclusión como guía para identificar inicialmente las publicaciones. De esta primera selección, se han eliminado aquellos documentos que después de una revisión más exhaustiva, se ha detectado que realmente no tenían nada que ver con el tema estudiado. Los autores y títulos de estos documentos se han importado a una Excel y se han descargado los documentos completos. A partir de estos documentos, se ha realizado una búsqueda del texto completo para excluir aquellos documentos que mencionan algunas palabras clave pero que no cubren el área temática de investigación. El resultado final ha dado un total de 31 publicaciones, que son las que se han analizado en profundidad para conseguir la información necesaria, en dos niveles diferentes: 1) un meta-análisis básico que indica las estadísticas cuantitativas del documento, incluyendo: año de publicación, revistas y autores; y 2) análisis temático para cada uno de los documentos, incluyendo: a) Marco teórico, b) Análisis de casos prácticos y c) Análisis estadísticos.

La Tabla 5 recoge los principales resultados del análisis bibliométrico correspondientes al meta-análisis básico. Por años, se produce una dispersión bastante alta, si bien los dos años con mayor número de publiaciones son el 2018 (5) y el 2020 (4). Las revistas en las que se ha publicado un mayor número de trabajo son 4, que concentran el 29\% del total, destacando el caso de la Journal of Social Policy con 3 publicaciones. El resto de revistas incluyen un solo artículo publicado. Entre los trabajos más citados destacan 3 con un número de citas superior a las 20: Fuller y Jonas (2002), Affleck y Mellor (2006) y Bhanot et al. (2012).

Tabla. 5. Resultados del meta-análisis básico del estudio bibliométrico

\begin{tabular}{|c|c|c|c|c|c|}
\hline \multicolumn{2}{|c|}{ Año publicación } & \multicolumn{2}{|l|}{ Revistas (número) } & \multicolumn{2}{|c|}{ Trabajos más citados (citas) } \\
\hline 2020 & 4 & Journal of Social Policy & 3 & Fuller y Jonas (2002) & 26 \\
\hline 2019 & 2 & Social Indicators Research & 2 & Affleck y Mellor (2006) & 26 \\
\hline 2018 & 5 & Pacific Business Review International & 2 & Bhanot et al. (2012) & 24 \\
\hline 2017 & 3 & International Journal of Social Economics & 2 & Cnaan et al. (2012) & 18 \\
\hline 2016 & 2 & $\begin{array}{l}\text { International Journal of Sociology and Social } \\
\text { Policy }\end{array}$ & 2 & Sinclair (2013) & 15 \\
\hline 2015 & 1 & Journal of Social Work & 1 & Devlin (2009) & 14 \\
\hline 2014 & 3 & Applied Economics & 1 & Fuller et al. (2006) & 12 \\
\hline 2013 & 3 & Information Technology for Development & 1 & Hohnen (2007) & 10 \\
\hline 2012 & 2 & Public Money \& Management & 1 & Salignac et al. (2016) & 10 \\
\hline 2010 & 1 & Polish Sociological Review & 1 & Kemal (2019) & 7 \\
\hline 2009 & 1 & CIRIEC-España & 1 & Fernández-Olit et al. (2018) & 6 \\
\hline 2007 & 1 & Journal of Enabling Technologies & 1 & Sinclair (2014) & 4 \\
\hline 2006 & 2 & $\begin{array}{l}\text { Strategic Changes-Briefings in Entrepre- } \\
\text { neurial Finance }\end{array}$ & 1 & Horska et al. (2013) & 3 \\
\hline 2002 & 1 & Revista Mexicana de Economía y Finanzas & 1 & Sain et al. (2016) & 3 \\
\hline \multirow[t]{2}{*}{ Total } & 31 & $\begin{array}{l}\text { Australasian Accounting Business and Finance } \\
\text { Journal }\end{array}$ & 1 & Kanyurhi (2017) & 3 \\
\hline & & Revista de Administraçao Pública & 1 & Birkenmaier y Fu (2018) & 2 \\
\hline
\end{tabular}




\begin{tabular}{|l|l|l|l|l|} 
& Policy and Politics & 1 & Klobukowska (2013) \\
& Social Welfare Policy & 1 & Mettenheim y Lima (2014) & 1 \\
\hline & Agricultural Economics & 1 & Wellalage, NH; Locke (2020) & 1 \\
\hline & Oeconomía Copernicana & 1 & & 1 \\
\hline & International Journal of Bank Marketing & 1 & & \\
\hline & Revue Interventions Economiques & 1 & & \\
\hline & Service Industries Journal & 1 & & \\
\hline & Sociological Review & 1 & & \\
\hline & Antipode & 1 & & \\
\hline
\end{tabular}

Fuente: elaboración propia.

La Tabla 6 recoge los principales resultados del análisis bibliométrico correspondientes al análisis temático.

Tabla. 6. Resultados del análisis temático del estudio bibliométrico

\begin{tabular}{|l|l|l|}
\hline \multicolumn{1}{|c|}{ Temática } & Número & \multicolumn{1}{c|}{$\%$} \\
Marco teórico & 9 & 29,03 \\
\hline Empírico cualitativo & 6 & 19,35 \\
Empírico cuantitativo & 16 & 51,61 \\
\hline Total & 31 & 100,00 \\
\hline
\end{tabular}

Fuente: elaboración propia.

Se observa que más del $50 \%$ de los trabajos corresponden a estudios empíricos mediante métodos cuantitativos $(51,61 \%)$, como son análisis descriptivos de datos secundarios, estudios de regresión múltiple, análisis multivariante, estudios longitudinales, etc. Los trabajos empíricos cualitativos, que representan el $19 \%$, han consistido en el análisis de casos y en entrevistas. Los trabajos teóricos suponen el $29 \%$ del total. Una parte de los trabajos analizados se centran en el estudio de la relación entre exclusión social y financiera enfocada a determinados colectivos como las mujeres (3), habitantes zonas rurales (2), personas discapacitadas (1), refugiados (1), personas sin hogar (1), personas mayores ciegas (1), comunidad musulmana (1) y hogares de bajos ingresos (1). También algunas publicaciones centran su estudio en países como India (5), Reino Unido (5), Polonia (2), Estados Unidos (2), Siria (1), Paquistán (1), Nigeria (1), México (1), Australia (1), Brasil (1), Corea (1) y Dinamarca y Suecia (1). El detalle de cada uno de estos trabajos (metodología utilizada y resultados obtenidos) se incorpora al análisis que se realiza a continuación.

En la relación existente entre exclusión financiera y social, se destaca lo problemático que puede llegar a ser que las personas no logren acceder a créditos o servicios financieros en economías capitalistas (Leyshon y Thrift, 1995 : 313), más aún cuando no se cuenta con los ingresos y con la educación general o financiera que les permita a colectivos de bajos ingresos acceder a estos servicios financieros, teniendo en cuenta la relevancia que tiene el sector bancario en el desarrollo de las economías (Iqbal y Sami, 2017; Nanda y Samanta, 2018; McGarity et al., 2020).

Wilson (2012) profundiza en la relación directa entre la vulnerabilidad y la exclusión financiera, refiriéndose a que, en el caso del contexto occidental y liberal, quienes viven la exclusión financiera son vulnerables a las presiones financieras, al incremento del coste de vida y a la exclusión social. De modo que con la exclusión financiera se limita a los colectivos vulnerables con posibilidades de inversión, lo que supone un crecimiento económico lento, teniendo en cuenta que las personas desempleadas o con empleos irregulares tienen menos probabilidades de participar en el sistema financiero (Sarma y Pais, 2011). Por tanto, la inclusión financiera está definitivamente relacionada con el crecimiento y el desarrollo de la economía (Iqbal y Sami, 2017; Nanda y Samanta, 2018). Es el caso de los colectivos vulnerables cuando tienen la oportunidad de participar en emprendimientos productivos, creando pequeñas empresas, intensificando la creación de empleo y poniendo en valor las iniciativas individuales de pequeña escala (Del Río, 2012; Kaur y Kapuria, 2020; Wellalage y Locke, 2020). 
Por otro lado, el acceso a una cuenta bancaria se traduce en el ingreso a la banca formal, lo que representa impulsar el ahorro y la aproximación a la obtención de créditos. De igual manera, da vía a la recepción de salarios, remesas y pagos, lo que implica un paso más a la igualdad a partir de un sistema financiero inclusivo (Demirguc-Kunt y Klapper, 2013). Hay que añadir además que las cuentas bancarias, el crédito del banco, los productos de ahorros, las remesas, los servicios de pago, seguros y las hipotecas están siendo reconocidos como factores de peso en el desarrollo económico (Arora, 2014).

Por tanto, en lo que se refiere a las dificultades sociales que forman parte de la exclusión social, éstas impulsan el proceso de exclusión financiera; y a su vez, los obstáculos para acceder al sistema financiero promueven el proceso de exclusión social, especialmente porque estos servicios se han puesto en el centro de la sociedad, en las relaciones sociales, familiares, de amigos, así como para recibir un salario por empleo, ayudas o consumo. De ello se deduce que la exclusión financiera se desarrolla como causa y efecto de la exclusión social (Gloukoviezoff, 2007). De ahí que el acceso y uso de una cuenta bancaria básica y las transacciones simples sean relevantes para la integración de las personas en la sociedad (Delvin, 2009; Anderloni et al., 2008). Coinciden en ello Fernández-Olit et al. (2018), dado que los obstáculos que tienen algunas personas o colectivos para estar incluidos en los servicios financieros en una sociedad altamente financiarizada, corren el riesgo de estar excluidos financieramente, originando un claro y directo factor de riesgo de pobreza o exclusión social y por tanto visibilizando la negativa relación existente entre el riesgo de exclusión social y el uso de los servicios bancarios que puede desencadenar en la vulnerabilidad financiera y la exclusión en las situaciones mucho más extremas. De igual modo, Anderloni et al. (2008) destacan la relación recíproca que existe entre la exclusión financiera y la exclusión social, reafirmando que una lleva casi automáticamente a la otra (Cnaan et al., 2012; Sinclair, 2013). Dicho de otra manera, el proceso de exclusión financiera eleva el riesgo de sufrir exclusión social. En consecuencia, las personas en condiciones de pobreza están más expuestas a estar en situación de exclusión financiera, dado que sus obstáculos principales tienen que ver con problemas financieros (Swamy, 2010; Dixit y Ghosh, 2013). Por lo cual, la pobreza y la desigualdad se podrían ver muy influenciadas por el nivel de acceso al ahorro formal de los hogares que cuentan con ingresos mínimos (Hohnen, 2007; Honohan, 2008).

Por otra parte, unas finanzas inclusivas promueven el desarrollo económico y el empleo, impulsando las ganancias y en consecuencia generando oportunidades e inclusión social (Fuller y Jonas, 2002; Affleck y Mellor, 2006; Demirguc-Kunt y Levine, 2009; Belmonte et al., 2013). Desde esta perspectiva, incluir financieramente a todos los grupos de personas en condición de exclusión social, pobreza e incluso de clase media, reduce las desigualdades y la pobreza, permite la adquisición de capital, aumentar las ganancias y afrontar los riesgos, especialmente en los países en vías de desarrollo (World Bank, 2008; Bhanot et al., 2012). Por tanto, el acceso al sistema bancario es en definitiva el motor de crecimiento inclusivo que beneficia el desarrollo empresarial, la educación, el consumo y el empleo e incluso tiene efectos positivos sobre la salud mental de las personas, lo que se traduce en disminución de la pobreza y de la exclusión social (World Bank, 2014). Coincide Kumar (2013) al destacar que unas condiciones económica óptimas y sólidas, que generen empleos y por tanto ingresos, promueve la inclusión financiera, dado que mejora el interés en las personas para participar en el sistema bancario. De igual manera, el acceso a servicios financieros para pequeños y medianos empresarios genera crecimiento inclusivo en la economía.

El desarrollo financiero y social de un territorio reduce su índice de pobreza, su entorno social y económico se vuelven más libres y su nivel de inclusión financiera aumenta. Este desarrollo dentro de un país también afecta positivamente a sus países vecinos. Hay que mencionar, además, que a diferencia de la exclusión financiera, la noción de inclusión financiera o financiación inclusiva está surgiendo simultáneamente con la conciencia de que se debe mejorar la vida de las personas en condición de pobreza. En los últimos años, la inclusión financiera ha ganado creciente interés como un objetivo político, llamando la atención de los legisladores y las administraciones públicas (Wang y Guan, 2017; Kemal, 2019). Por tanto, para la construcción de sociedades financieras incluyentes se requiere reducir la desigualdad de ingresos, mejorar los niveles de alfabetización, la infraestructura física y de comunicación, y de igual forma, formular políticas de apoyo y confianza para los bancos nacionales y evitar de esta manera la propagación de la banca extranjera (Sarma y Pais, 2011). Por tanto, "Las personas en situación de pobreza o riesgo de exclusión no pueden acceder a un número considerable de bienes y servicios, entre los cuales se encuentran los servicios financieros. Aunque los productos y servicios financieros no se consideran bienes de primera necesidad, como sí lo son la comida o la ropa, su carencia o falta de acceso puede ocasionar mayor pobreza y riesgo de exclusión social al hacer más difícil la posibilidad de participar activamente en la vida económica y social y, por tanto, de integrarse económica y socialmente, por lo que se hace necesario tomar medidas para paliar también la exclusión financiera. A su vez, la exclusión financiera produce más exclusión social, creándose un círculo vicioso difícil de romper" (Sanchis, 2016: 55).

Es relevante tener en cuenta además que con posterioridad a la última crisis financiera mundial del 2008, la relación causa y efecto entre la exclusión social y financiera ha ganado relevancia en países de la zona Euro y de los Estados Unidos. En esas economías, hay un número alto de personas que no se encuentra bancarizado, especialmente en aquellos hogares con bajos ingresos y baja educación. Estas personas no 
cuentan con acceso a los instrumentos de ahorro y préstamo que ofertan las instituciones financieras formales $\mathrm{y}$, por tanto, tienden a estar en desventaja económica y en consecuencia a no poder consumir y se enfrentan a más dificultades para acumular riqueza (Fraile y Ehrmann, 2016).

Habría que decir también que las finanzas reducen la desigualdad a través de mecanismos indirectos del mercado laboral. Además, el desarrollo financiero afecta positivamente al crecimiento económico, potencia la competencia e intensifica la demanda de mano de obra, generando beneficios en las personas que se encuentran en el extremo inferior de la distribución del ingreso (Demirgurc-Kunt y Levine, 2009). De manera que la inclusión social es importante por sí misma, pero también es importante porque es la base para la prosperidad compartida y porque la exclusión social es demasiado costosa. Hay costes considerables, de carácter social, político y económico, cuando no se aborda la exclusión de grupos completos de personas (World Bank, 2013).

Por su parte, Sarma y Pais (2011) plantean que las relaciones conceptuales y funcionales entre inclusión social y exclusión financiera tienen su punto de encuentro cuando los colectivos o grupos sociales al margen de la sociedad o en riesgo de exclusión social, no pueden acceder a servicios financieros. La conexión surge también cuando la inclusión financiera y el desarrollo humano se integran de manera muy positiva; y, por el contrario, dejan ver a la exclusión financiera como un reflejo de la exclusión social. Es el caso de los países con bajo PIB per cápita, con altos índices de desigualdad en cuanto a ingresos, alfabetización, vivienda y conectividad que llegan a ser menos inclusivos desde el punto de vista financiero.

Aunque el presente trabajo se centra en el estudio teórico de la relación causa-efecto entre la exclusión/inclusión financiera y social, se ha considerado oportuno hacer referencia a algunos trabajos empíricos, cuyos resultados redundan en los aspectos apuntados a nivel teórico. Así, Fernández-Olit et al. (2018), utilizan el análisis multivariante aplicado a la encuesta sobre vulnerabilidad social realizada por la Cruz Roja Española en 2015 para demostrar que las personas en riesgo de exclusión y pobreza que están integradas dentro del sistema financiero presentan menores probabilidades de acabar en situación de exclusión o pobreza. Sus resultados respaldan las recomendaciones de varios autores: reducir los requisitos de documentación al abrir una cuenta bancaria (Allen et al., 2012), ofrecer paquetes simples con costes claros y fijos, mejorar la comunicación con respecto a los criterios para otorgar crédito y facilitar sin antecedentes bancarios en el caso de los inmigrantes, así como alentar las remesas a través de los bancos (Anderloni y Carluccio, 2007; Wellalage y Locke, 2020). Por su parte, el trabajo de Anderloni et al. (2008) recoge una revisión de investigaciones realizadas sobre la exclusión/inclusión financiera en 14 países de la Unión Europea y demuestra que la exclusión financiera se da con mayor intensidad en aquellas personas y colectivos donde existe exclusión social y se reconoce que la primera forma parte de la segunda. Barr (2004) relaciona los servicios financieros con los niveles de renta de las personas y concluye que cuantas más dificultades se tienen para acceder a servicios financieros, mayor probabilidad de sufrir una exclusión social (Salignac et al., 2016; Kemal, 2019). Por último, el Rangarajan Commitee (2008) realizó un estudio sobre la inclusión financiera en India, para concluir que el acceso a la financiación por parte de los grupos pobres y vulnerables es un requisito previo para la reducción de la pobreza y la cohesión social; este informe es respaldado por otros trabajos que recogen también la situación en India (Cnaan et al., 2012; Nanda et al., 2017; Kaur y Kapuria, 2020).

\section{Conclusiones}

El estudio realizado sobre la relación existente entre la exclusión/inclusión financiera y la exclusión/inclusión social nos ha permitido identificar los puntos comunes entre las dos dimensiones (social y financiera) representados en fenómenos como: 1) en el caso de la exclusión: pobreza, vulnerabilidad, calidad de vida, discriminación, desigualdad y otras situaciones de tipo socioeconómico; y 2) en el caso de la inclusión: calidad de vida, desarrollo, participación, bienestar, oportunidades, políticas y otros procesos sociales.

Se ha realizado un análisis detallado sobre las causas que producen la exclusión/inclusión financiera, destacando entre las mismas la falta de cultura financiera, el abuso por parte de las instituciones financieras y las malas prácticas comerciales, las dificultades de acceso tecnológico, la calidad del entorno institucional, la inseguridad laboral y determinadas condiciones socioeconómicas como son la falta de ingresos, la inmigración, tener rentas bajas o la autoexclusión. Por otra parte, entre las causas de la exclusión/inclusión social se destacan la pobreza, determinadas condiciones adicionales como edad, género, raza, etc., el contexto o condiciones particulares de cada persona, desempleo y precarización y brechas sociales. Relacionando las causas de un tipo de exclusión y del otro se observa que existen elementos o aspectos comunes, lo que demuestra la fuerte conexión entre la exclusión financiera y la exclusión social.

Se puede concluir que a mayor exclusión financiera, mayor exclusión social y a mayor exclusión social mayor exclusión financiera. La relación entre ambos conceptos es directa y recíproca (Swamy, 2010; Sarma y Pais, 2011; Sánchez Macías y Rodríguez López, 2015). De tal manera que la inclusión tanto financiera 
como social pasan a convertirse en una herramienta o alternativa para disminuir los efectos de los fenómenos sociales que provocan la desigualdad (Del Río Piovich, 2012). Esta relación recíproca entre ambos conceptos ha sido analizada empíricamente en diferentes trabajos, recogiendo estudios tanto en países en desarrollo o con unos niveles de pobreza elevados y fuertes desigualdades (India, Polonia, Brasil, Paquistán, Nigeria, Siria o México) (Bhanot et al. 2012; Cnaan et al., 2012; Salazar et al., 2017; entre otros) como en países desarrollados pero donde también se manifiesta la exclusión social y la pobreza (Estados Unidos, Reino Unido, Australia y Dinamarca y Suecia) (Devlin, 2009; Sinclair, 2013; Sain et al., 2016; Birkenmaier y Fu, 2018; entre otros). El análisis bibliométrico realizado nos ha permitido identificar dichos casos. Además, este fenómeno se da con mayor intensidad y claridad durante las épocas de crisis económicas como la crisis financiera de 2008 o la crisis sanitaria de 2020 (Nanda y Samanta, 2018).

La exclusión financiera amplía la brecha de pobreza, dado que cuando las personas especialmente en condición de vulnerabilidad no cuentan con los recursos necesarios para acceder a servicios y productos financieros, pueden acabar enfrentándose a situaciones como: imposibilidad de obtener un crédito a bajo coste para una vivienda o estudio, pagar los insumos para el trabajo rural, desarrollar un emprendimiento, acceder a subvenciones sociales, ahorrar para la vejez, pagar facturas, etc.. Con tales riesgos, las personas pueden adentrarse fácilmente en la exclusión social y en consecuencia caer en ese ciclo continuo y vicioso de exclusión como causa y efecto. Si además se tiene en cuenta que la exclusión financiera se acentúa en contextos favorables a la exclusión social (zonas rurales, territorios desfavorecidos, ...), ésta produce un efecto multiplicador en la exclusión social. De ahí que se defienda la necesidad de mantener un sistema bancario que incluya modelos de banca de proximidad, social y ética, representada por entidades de crédito como las cajas de ahorros, las cooperativas de crédito, la banca ética y la banca pública (Sinclair, 2014; Nanda et al., 2017).

Por otro lado, la relación positiva entre inclusión financiera y social produce un efecto positivo en el desarrollo económico y social de un país. De ahí que cuando una persona o un grupo de personas acceden a servicios y productos financieros formales y de bajos costes, tienen la posibilidad de mejorar su calidad de vida y participar activamente en la vida económica y social de sus territorios, disminuyendo las desigualdades sociales; del mismo modo que cuando disminuyen las desigualdades sociales, se facilita el acceso a los servicios y productos financieros, reduciendo la exclusión financiera. La inclusión financiera permite crear las condiciones apropiadas para favorecer el desarrollo económico y social y, por tanto, reducir o paliar las desigualdades y la pobreza, es decir, la exclusión social. Por este motivo, la educación financiera puede representar una medida que no solo favorece la inclusión financiera, si no que sobre todo crea las bases para la inclusión social (Devlin, 2009; Kaur y Kapuria, 2020). Del mismo modo, la existencia de un modelo bancario inspirado en la inclusión financiera (banca de proximidad, cooperativa y ética) crea las bases para un mayor desarrollo económico y social, contribuyendo positivamente a la inclusión social (Sinclair, 2014). Los estudios empíricos identificados con el análisis bibliométrico realizado concluyen que existen una serie de variables o factores clave que desde la inclusión financiera favorecen la inclusión social. Entre estos factores se pueden destacar principalmente la educación financiera (Devlin, 2009; Nanda y Samanta, 2018; McGarity et al., 2020; Kaur y Kapuria, 2020), las tecnologías bancarias (Okonji y Ogwezzy, 2018; Kemal, 2019), la proximidad bancaria (Bhanot et al., 2012) y las finanzas sostenibles o éticas (Fuller y Jonas, 2002; Affleck y Mellor, 2006).

No obstante, también existen estudios empíricos que demuestran que las medidas financieras y económicas adoptadas por las administraciones públicas y por el propio sistema financiero no son suficientes para resolver el problema de la exclusión financiera y de la exclusión social al generar restricciones de tipo humano y sociológico (Kemal, 2019), la pérdida de protección legal (Jakibowska y Grochowski, 2019), cambios económicos (Nanda y Samanta, 2018), uso del dinero electrónico (Hohnen, 2007) o al tener un alcance limitado (Sinclair, 2012). Todos estos estudios, aunque reconocen determinados efectos positivos en las acciones enfocadas a la inclusión financiera para paliar la exclusión social, también son críticos con las medidas adoptadas y destacan la existencia de límites en los efectos de las medidas adoptadas para favorecer la inclusión financiera, sobre todo cuando se trata de actuar sobre los niveles de pobreza y de exclusión social.

El presente trabajo no permite profundizar en la cuestión planteada sobre los límites en las medidas contra la exclusión financiera y sus efectos positivos sobre la exclusión social (y viceversa), al tratarse de un trabajo teórico cuyo único objetivo es realizar una primera aproximación conceptual a la relación entre ambos conceptos (social y financiera), con el objeto de señalar la relevancia de esa relación causa-efecto entre ellos. No obstante, sí permite sentar las bases para investigaciones futuras, al recoger los principales factores que determinan dicha relación, a partir de los diferentes trabajos empíricos estudiados con el análisis bibliométrico. El estudio ha dejado claro cuáles son los factores determinantes de la inclusión social y financiera, como ya se ha apuntado y se ha constatado en los trabajos empíricos analizados.

En este sentido, las investigaciones posteriores irían en la línea de establecer propuestas de implantación de políticas públicas que potencien los efectos de dicha relación. En el análisis de la definición y relación de los conceptos se han encontrado dificultades derivadas de la existencia de escasos trabajos publicados sobre 
el tema. Si bien existen numerosos trabajos que apoyan los conceptos de exclusión/inclusión financiera y de exclusión/inclusión social, los trabajos que analizan las relaciones causa-efecto entre ambas dimensiones son más bien escasos, como se ha podido constatar. Por otra parte, existen múltiples definiciones de ambos conceptos (financiera y social), que abordan el tema desde perspectivas muy diversas y heterogéneas, lo que dificulta ofrecer una definición consensuada de los mismos. Ambos conceptos suelen analizarse más como procesos, lo que dificulta su delimitación conceptual. En lo que respecta a la inclusión/exclusión financiera aparecen múltiples definiciones, que son fijadas tanto por trabajos teóricos como por organismos multilaterales públicos y privados y que más que ofrecer una definición, lo que hacen es analizar sus características, factores y condiciones. Por parte de las dimensiones sociales, las limitaciones surgen en el mismo sentido, encontrar definiciones exactas, pues de hecho suelen presentarse algunos conceptos de inclusión social en el mismo sentido que el de integración social y partiendo de estudios sociológicos, filosóficos o de trabajo social que resaltan los efectos de la inclusión, pero en situaciones bastante específicas de sus líneas de investigación o actuación. En el caso de la exclusión social, algunos estudios la presentan con el mismo concepto de inclusión, pero con negación, por ejemplo, no acceso, no poder ingresar, no pertenecer, etc.; lo que hace difícil separar la definición más allá de la negación (Hernández, 2008; United Nations, 2010).

En trabajos posteriores se pretenderá también analizar el fenómeno de la relación causa-efecto entre la exclusión/inclusión financiera y la exclusión/inclusión social desde el punto de vista empírico, reforzando así las argumentaciones teóricas expuestas en el presente trabajo. Por este motivo, puede resultar de interés realizar un estudio de casos, que relacione el papel que determinados bancos inclusivos o sostenibles (éticos, cooperativos, de proximidad) mantienen con la contribución a la inclusión social entre diferentes tipos de colectivos o comunidades, como ya se señala en algunos trabajos publicados (Sinclair, 2014; Lee y Carlisle, 2020). También puede ser de interés realizar un análisis comparativo de casos entre bancos sostenibles y bancos convencionales, con el fin de demostrar que los primeros contribuyen en mayor medida que los segundos a la inclusión social.

Nos situamos ante un tema de actualidad, como es la relación entre inclusión financiera e inclusión social, que requiere de un mayor número de trabajos, tanto teóricos como empíricos, que aborden las relaciones causa-efecto entre ambos conceptos y permitan proponer medidas de apoyo al desarrollo económico y social del territorio y las personas. El presente trabajo tenía como propósito demostrar la existencia de dicha relación de causa-efecto desde un punto de vista teórico y ofrecer una definición más clara de ambos conceptos, planteando así la necesidad de abordar el tema con mayor profundidad.

\section{Referencias bibliográficas}

Adkins, N. R.; Ozanne, J. L. (2005) The low literate consumer. Journal of Consumer Research, Vol. 32, № 1, pp. 93105.

Affleck, A.; Mellor, M. (2006) Community development finance: A neo-market solution to social exclusion?. Journal of Social Policy, $\mathrm{N}^{\mathrm{o}} 35$, pp. 303-319.

Albers, M. B. (2007) What types of neighbourhoods are redlined?. Journal of Housing and the Built Environment, Vol. 22, $\mathrm{N}^{\mathrm{o}} 2$, pp. $177-198$.

Allen, F., Demirguc-Kunt, A., Klapper, L., Peria, M. S. M. (2016) The foundations of financial inclusion: Understanding ownership and use of formal accounts. Journal of Financial Intermediation, No 27, pp. 1-30.

Álvarez, B. S. (2016) ¿Inclusión en qué?. Conceptualizando la inclusión social. EHQUIDAD, Revista Internacional de Políticas de Bienestar y Trabajo Social, № 5, pp. 71-108.

Anderloni, L.; Carluccio, E. M. (2007) Access to bank accounts and payment services. New frontiers in banking services. Springer Berlin Heidelberg, pp. 5-105.

Anderloni, L.; Bayot, B.; Błędowski, P.; Iwanicz-Drozdowska, M.; Kempson, E. (2008) Financial Services Provision and Prevention of Financial Exclusion: European Commission Directorate General for Employment. Social Affairs and Equal Opportunities. https://www.bristol.ac.uk/medialibrary/sites/geography/migrated/documents/pfrc0807.pdf.

Ampudia Fraile, M.; Ehrmann, M. (2016) Financial Inclusion-What's it Worth?. Bank of Canada.

Arora, R. U. (2014) Access to finance: an empirical analysis. The European Journal of Development Research, Vol. 26, $\mathrm{N}^{\mathrm{o}} 5$, pp. 798-814.

Arora, R. U. (2018) Financial inclusion: understanding concept, barriers and measurement. En Mohammed, E.Y. y Uraguchi, Z.B. (Eds.) Financial inclusion for poverty alleviation: issues and case studies for sustainable development. London: Routledge.

Arroyo Abad, C. (2013) Exclusión social y empresas de inserción. Anuario Jurídico y Económico Escurialense, № 46 , pp. 191-202.

Baker, S. M.; Mason, M. (2012) Toward a process theory of consumer vulnerability and resilience: Illuminating its transformative potential. En Mick, R. G. (Ed.) Transformative Consumer Research for Personal and Collective Well-being. New York: Routledge; pp. 543-564. 
Barr, M. S. (2004) Banking the poor. Yale Journal on Regional, № 21, pp. 121-129.

Beck, T.; Demirguc-Kunt, A.; Martinez Peria, M. S. (2007) Reaching Out: Access to and Use of Banking Services Across Countries. Journal of Financial Economics, No 85, pp. 234-266.

Beck, T.; Demirguc-Kunt, A.; Honohan, P. (2009) Access to financial services: Measurement, impact and policies. World Bank Research Observer, Vol. 24, № 1, pp. 119-145.

Belmonte Ureña, L. J.; Cortés García, F. J.; Molina Moreno, V. (2013) Las cooperativas de crédito españolas y la lucha contra la exclusión financiera. Cooperativismo \& Desarrollo, Vol. 21, No 103, pp. 49-55.

Bhanot, D.; Bapat, V.; Bera, S. (2012) Studying financial inclusion in north-east India. International Journal of Bank Marketing, Vol. 30, No 6, pp. 465-484.

Birkenmaier, J.; Fu, Q. (2018) Household Financial Access and Use of Alternative Financial Services in the US: Two Sides of the Same Coin?. Social Indicators Research, Vol. 139, No 3, pp. 1169-1185.

Bowman, A.; Erturk, I.; Froud, J.; Johal, S.; Law, J.; Leaver, A.; Salento, A.; Engelen, E. (2014) The end of the experiment. Manchester: Manchester University Press.

Bradshaw, J.; Gordon, D.; Levitas, R.; Middleton, S.; Pantazis, C.; Payne, S.; Townsend, P. (1998) Perceptions of poverty and social exclusion. Bristol: Townsend Centre for International Poverty Research.

Carbó, S.; Rodríguez, F. (2015) Concepto y evolución de la exclusión financiera: Una revisión. Cuadernos de Información Económica, $\mathrm{N}^{\circ}$ 244, pp. 73-83.

CEPAL (2015) Panorama Social de América Latina. Santiago De Chile: Naciones Unidas, Comisión Económica para América Latina y el Caribe (CEPAL). Recuperado de: https://www.cepal.org/es/publicaciones/39965-panoramasocial-america-latina-2015.

Cnaan, R. A.; Moodithaya, M. S.; Handy, F. (2012) Financial Inclusion: Lessons from Rural South India. Journal of Social Policy, No 41, pp. 183-205.

Cull, R.; Ehrbeck, T.; Holle, N. (2014) La inclusión financiera y el desarrollo: pruebas recientes de su impacto. Enfoques, $\mathrm{N}^{\circ}$ 92, pp. 1-11.

Chuaqui, J.; Mally, D.; Parraguez, R. (2016) El concepto de inclusión social. Revista de Ciencias Sociales, N 69, pp. 157-188.

De la Cruz-Ayuso, C. (2016) Exclusión Financiera, Vulnerabilidad y Subordiscriminación. Análisis crítico sobre el derecho al acceso a servicios bancarios básicos en la Unión Europea. Cuadernos Electrónicos de Filosofía del Derecho, No 34, pp. 91-114.

De Meza, D.; Irlenbusch, B.; Reyniers, D. (2008) Financial capability: A behavioural economics perspective. London: Financial Services Authority.

De la Orden, M. D. C. (2015) La banca islámica como herramienta de inclusión financiera. Opción, Vol. 31, № 6, pp. 211-228.

Del Río Piovich, M. (2012) Finanzas productivas para la inclusión y el desarrollo. Boletín de Estudios Económicos, Vol. 67, No 206, pp. 365-381.

Demirguc-Kunt, A.; Levine, R. (2009) Finance and inequality: Theory and evidence. Annuary Review Financial Economics, Vol. 1, № 1, pp. 287-318.

Demirguc-Kunt, A.; Klapper, L. (2013) Measuring financial inclusion: Explaining variation in use of financial services across and within countries. Brookings Papers on Economic Activity, No 1, pp. 279-340.

Devlin, J. F. (2009) An analysis of influences on total financial exclusion. Service Industries Journal, Vol. 29, № 8, pp. 1021-1036.

Dixit, R.; Ghosh, M. (2013) Financial inclusion for inclusive growth of India-A study of Indian states. International Journal of Business Management \& Research, Vol. 3, № 1, pp. 147-156.

European Commission. (2004) Joint report on social inclusion. Brussels, Belgium: Council of the European Union. https://ec.europa.eu/employment_social/social_inclusion/docs/final_joint_inclusion_report 2003 en.pdf.

Fabre, M. M. (2000) Consideraciones en torno al concepto de exclusión social. Acciones e investigaciones sociales, $\mathrm{N}^{\circ}$ 11, pp. 9-22.

Fernández-Olit, B. (2012) Financial inclusion in Spain: a comparative study among Banks, Savings Banks and Cooperative Banks, Perspectives No 65. European Savings Banks Group.

Fernández-Olit, B. (2016) Tendencias de la exclusión financiera: efectos de la transformación del sector bancario español. Tesis Doctoral. UNED (España). Facultad de Ciencias Económicas y Empresariales. Departamento de Economía Aplicada. Recuperada de: https://dialnet.unirioja.es/servlet/tesis?codigo=66466.

Fernández-Olit, B. (2020) Modelo bancario e inclusion financiera del territorio español durante la Gran Recesion: un analisis comparativo entre Banca Social, Cooperativa y Comercial. REVESCO. Revista de Estudios Cooperativos, vol. 135, e69187. https://dx.doi.org/10.5209/reve.69187.

Fernández-Olit, B.; Paredes-Gázquez, J. D.; De la Cuesta-González, M. (2018) Are Social and Financial Exclusion Two Sides of the Same Coin?. An Analysis of the Financial Integration of Vulnerable People. Social Indicators Research No 135, pp. 245-268. https://doi.org/10.1007/s11205-016-1479-y.

Fuertes, A.; Chowdhury, N. I. (2009) Los microcréditos como instrumento de erradicación de la pobreza. Pobreza y libertad: erradicar la pobreza desde el enfoque de las capacidades de Amartya Sen. Tecnos, pp. 235-262.

Fuller, D.; Jonas, A. E. G. (2002) Institutionalising future geographies of financial inclusion: National legitimacy versus local autonomy in the British credit union movement. Antipode, Vol. 34, No 1, pp. 85-110. 
Fuller, D.; Mellor, M.; Dodds, L.; Affleck, A. (2006) Consulting the community Advancing financial inclusion in Newcastle upon Tyne, UK. International Journal of Sociology and Social Policy, Vol. 26, № 5-6, pp. $255-271$.

Gordon, D. (1998) Definitions of concepts for the perceptions of poverty and social exclusion. Perceptions of Poverty and Social Exclusion 1998. Report on Preparatory Research.

G-20. (2012) Financial Inclusion Indicators. Grupo de Inclusión Financiera. Recuperado de: https://www.gpfi.org/news/g20-financial-inclusion-indicators.

GPFI CGAP. (2011) Global Standard-Setting Bodies and Financial Inclusion for the Poor -Toward Proportionate Standards and Guidance, White Paper, octubre, Washington D. C.

Gloukoviezoff, G. (2007) From financial exclusion to overindebtedness: The paradox of difficulties for people on low incomes? Berlin, Heidelberg: Springer Berlin Heidelberg, pp. 213-245. doi:10.1007/978-3-540-46498-3_6.

Gómez-Barroso, J. L.; Marbán-Flores, R. (2013) Basic financial services: A new service of general economic interest?. Journal of European Social Policy, Vol. 23, № 3, pp. 332-339.

Hernández, M. (2008) Exclusión social y desigualdad. Servicio de publicaciones. Murcia: Universidad de Murcia.

Hohnen, P. (2007) Having the wrong kind of money. A qualitative analysis of new forms of financial, social and moral exclusion in consumerist Scandinavia. Sociological Review, Vol. 55, No 4, pp. 748-767.

Honohan, P. (2008) Cross-country variation in household access to financial services. Journal of Banking \& Finance, Vol. 32, No 11, pp. 2493-2500.

Horska, E.; Szafranska, M.; Matysik-Pejas, R. (2013) Knowledge and financial skills as the factors determining the financial exclusion process of rural dwellers in Poland. Agricultural Economics-Zemedelska Ekonomika, Vol. 59, N ${ }^{\circ}$ 1, pp. 29-37.

Ipsos, M. (2013) Road to Inclusion. MasterCard and Ipsos Mori: A look at the financially underserved and excluded across Europe. White paper for Mastercard Worldwide.

Iqbal, B.; Sami, S. (2017) Role of banks in financial inclusion in India. Contaduría y Administración, Vol. 62, № 2, pp. 644-656.

Joassart-Marcelli, P.; Stephens, P. (2009) Immigrant banking and financial exclusion in Greater Boston. Journal of Economic Geography, Vol. 10, № 6, pp. 883-912.

Johnson, M. P.; Schaltegger, S. (2016) Two decades of sustainability management tools for SMEs: how far have we come?. Journal of Small Business Management, Vol. 54, № 2, pp. 481-505.

Kanyurhi, E. B. (2017) Customer satisfaction with the services of microfinance institutions: Scale development and validation. Strategic Change-Briefings in Entrepreneurial Finance, Vol. 26, № 6, pp. 563-574.

Kaur, S.; Kapuria, C. (2020) Determinants of financial inclusion in rural India: does gender matter?. International Journal of Social Economics, Vol. 47, Nº 6, pp. 747-767.

Kemal, A. A. (2019) Mobile banking in the government-to-person payment sector for financial inclusion in Pakistan. Information Technology for Development, Vol. 25, No 3, pp. 475-502.

Kempson, H.; Whyley, C. (1999) Kept out or opted out?: Understanding and combating financial exclusión. http://www.bris.ac.uk/media-library/sites/geography/migrated/documents/pfrc9902.pdf.

Kempson, E.; Whyley, C.; Caskey, J.; Collard, S. (2000) In or out?: Financial exclusion: Literature and research review, Consumer Research, Financial Services Authority.

Kempson, E.; Crame, M.; Finney, A. (2007) Financial services provision and prevention of financial exclusion. Eurobarometer Report, University of Bristol. Recuperado de: http://www.bristol.ac.uk/medialibrary/sites/geography/migrated/documents/pfrc0808.pdf.

Kumar, N. (2013) Financial inclusion and its determinants: evidence from India. Journal of Financial Economic Policy, Vol. 5, No 1, pp. 4-19.

Lee, B.; Carlisle, L. (2020) A case study of the financial benefits of a credit union's homeless prevention scheme. Public Money \& Management, Vol. 40, No 1, pp. 63-71.

Levitas, R. (1998) Social exclusion in the new breadline Britain survey. Perceptions of Poverty and Social Exclusion, $\mathrm{N}^{\mathrm{o}} 41$, pp 91-110.

Levitas, R.; Pantazis, C.; Fahmy, E.; Gordon, D., Lloyd, E.; Patsios, D. (2007) The multi-dimensional analysis of social exclusion. Bristol, UK: University of Bristol.

Leyshon, A.; Thrift, N. (1995) Geographies of Financial Exclusion: Financial Abandonment in Britain and the United States. Transactions of the Institute of British Geographers, New Series.

Llorente San Segundo, I. (2019) Exclusión financiera e igualdad de trato en el acceso a servicios bancarios (No. ART2019-111521).

Loisy, C. (2000) Pauvreté, précarité, exclusion. Définitions et concepts. Observatoire national de la pauvreté et de l'exclusion sociale, Les travaux de l'Observatoire national de la pauvreté et de l'exclusion sociale, Paris: La Documentation française, pp. 23-50.

Marimuthu, S.; Mathan, J. (2015) Rural Perspective towards Financial Inclusion. Journal of Economic and Social Thought, Vol. 2, No 2, pp. 106-120.

Maudos, J. (2020) Resiliencia de la banca española frente a la crisis del COVID-19: comparativa europea. Cuadernos de Información económica, № 276, pp. 41-49.

McGarity, S.V.; Okech, D. O.; Risler, E.; Clees, T. J. (2020) Assessing financial capability among people with disabilities. Journal of Social Work, Vol. 20, № 5, pp. 657-672. 
Moustaghfir, K. (2008) The dynamics of knowledge assets and their link with firm performance. Measuring Business Excellence, Vol. 12, No 2, pp. 10-24.

Nanda, K.; Kaur, B.; Nanda, P. (2017) SHG - Bank Linkage: A Case Study of Amritsar District. Pacific Business Review International, Vol. 9, No 9, pp. 19-28.

Nanda, A. K.; Samanta, S. (2018) Mainstreaming tribals through financial literacy - a review of literature. International Journal of Social Economics, Vol. 45, N² 2, pp. 437-444.

Nemecio, J. L. (2020) Determinaciones socioambientales del COVID-19 y vulnerabilidad económica, espacial y sanitario-institucional, Revista de Ciencias Sociales, Vol. 26, № 2, pp. 21-26.

Nieto-Morales, C. (2012) Vulnerabilidad, desempleo y exclusión social en el siglo XXI. Nuevos tiempos, nuevos retos, nuevas sociologías, pp. 456-469.

OCDE. (2007) Society at a glance. OECD social indicators 2006. París: ocde. Recuperado de: https://www.oecdilibrary.org/docserver/soc glance-2006en.pdf?expires=1579534257\&id=id\&accname=guest\&checksum=0A8BA0664AB9F9CE47503F043C5321EE.

OCDE/INFE. (2013) Financial literacy and inclusion: Results of oecd/infe survey across countries and by gender. https://www.oecd.org/daf/fin/financialeducation/TrustFund2013_OECD_INFE_Fin_Lit_and_Incl_SurveyResults_b y_Country and_Gender.pdf.

Okonji, P. E.; Ogwezzy, D. C. (2018) Financial inclusion: perceptions of visually impaired older Nigerians. Journal of Enabling Technologies, Vol. 12, № 1, pp. 10-21.

Oliver, A. M.; Pardo, S. R. (2015) Restructuración bancaria y accesibilidad a los servicios financieros en España. Un análisis desde la competencia espacial". Papeles de Economía Española, N 146, pp. 180-198.

Petticrew, M.; Roberts, H. (2006) Systematic reviews in the social sciences: a practical guide, Oxford: Blackwell Publishing.

Rangarajan Commitee (2008) Report of the committee on financial inclusión. Ministry of Finance, Government of India. ISO 690 en http://slbckarnataka.com/UserFiles/slbc/Full\%20Report.pdf.

Sain, M. R. M.; Rahman, M. M.; Khanam, R. (2016) Financial Exclusion in Australia: Can Islamic Finance Minimise the Problem?. Australasian Accounting Business and Finance Journal, Vol. 10, № 3, pp. 89-104.

Sánchez Macías, J. I.; Rodríguez López, F. (2015) Educación financiera para la inclusión financiera: una hoja de ruta. Extoikos, № 17, pp. 17-20.

Salazar Cantú, J. J.; Rodríguez Guajardo, R. C.; Jaramillo Garza, J. (2017) Inclusión financiera y cohesión social en los municipios de México. Revista Mexicana de Economía y Finanzas, Vol. 12, № 3, 45-66.

Salignac, F.; Muir, K.; Wong, J. (2016) Are you really Financially Excluded if you Choose not to be Included? Insights from Social Exclusion, Resilience and Ecological Systems. Journal of Social Policy, Vol. 45, No 29, pp. $269-286$.

Sanchis Palacio, J. R. (2013). La banca que necesitamos: De la crisis bancaria a la banca ética: Una alternativa socialmente responsable. Valencia: Publicacions de la Universitat de València.

Sanchis Palacio, J.R. (2016) ¿Es Posible un mundo sin bancos?. La revolución de las finanzas éticas y solidarias. Barcelona: Editorial El Viejo Topo.

Sarma, M.; Pais, J. (2011) Financial inclusion and development. Journal of International Development, Vol. 23, № 5, pp. 613-628.

Servet, J. M. (2001) Exclusion bancaire et financière. Un essai de définition. Conferencia ofrecida en el marco del Encuentro Pour de nouvelles réponses à l'exclusion bancaire, en el Institut de Recherche pour le Développement.

Sinclair, S. P. (2001) Financial exclusion: An introductory survey. Report of Centre for Research in Socially Inclusive Services, Heriot-Watt University, Edinburgh, Scotland.

Sinclair, S. P. (2013) Financial inclusion and social financialisation: Britain in a European context. International Journal of Sociology and Social Policy, Vol. 33, № 11-12, pp. 658-677.

Sanclair, S. P. (2014) Credit union modernisation and the limits of voluntarism. Policy and Politics, Vol. 42, No 3, pp. 403-419.

Subirats, J.; Alfama, E.; Pineda, A. O. (2009) Ciudadanía e inclusión social frente a las inseguridades contemporáneas. La significación del empleo. Documentos de Trabajo (Fundación Carolina), № 32, 133-142.

Swamy, V. (2010) Financial development and inclusive growth: impact of government intervention in prioritised credit. Zagreb International Review of Economics \& Business, Vol. 13, № 2, pp. 55-72.

Tezanos, J. F. (2001) La sociedad dividida. Estructura de clases y desigualdades en las sociedades tecnológicas avanzadas. Madrid: Biblioteca Nueva.

Toset, E. M. J. (2009) Vulnerabilidad, exclusión social, desigualdad y ciudadanía. El trabajo social ante situaciones de desigualdades estructurales. Documentos de trabajo social: Revista de trabajo y acción social, № 45, pp. 9-57.

Tranfield, D.; Denyer, D.; Smart, P. (2003) Towards a methodology for developing evidence-informed management knowledge by means of a systematic review. British Journal of Management, No 14, pp. 207-222.

United Nations. (2010) Analysing and measuring social inclusion in a global context: Department of Economic and Social Affairs. Recuperado de: www.un.org/esa/socdev/publications/measuring-social-inclusion.pdf.

Wellalage, N. H.; Locke, S. (2020) Remittance and financial inclusion in refugee migrants: inverse probability of treatment weighting using the propensity score. Applied Economics, Vol. 52, No 9, pp. 929-950.

Wilson, T. A. (2012) Supporting social enterprises to support vulnerable consumers: the example of community development finance institutions and financial exclusion. Journal of Consumer Policy, Vol. 35, № 2, pp. $197-213$. 
World Bank. (2007) Social exclusion and the EU's social inclusion agenda. Recuperado de: http://siteresources.worldbank.org/INTECONEVAL/Resources/SocialExclusionReviewDraft.pdf.

World Bank. (2008) Finance for all? Policies and pitfalls in expanding Access. Policy Research Report, 2007033387, World Bank,. Washington, DC, USA. Recuperado de: https://openknowledge.worldbank.org/bitstream/handle/10986/6905/417920PAPER0Fi18082137291301PUBLIC1.p df?sequence $=1 \&$ isAllowed $=\mathrm{y}$.

World Bank. (2013). Inclusion Matters: The Foundation for Shared Prosperity-Overview. Washington, DC: World Bank.

World Bank. (2014). Global financial development report 2014 : financial inclusion (English). Global financial development report. Washington, DC : World Bank Group. Recuperado de: http://documents.worldbank.org/curated/en/225251468330270218/Global-financial-development-report-2014financial-inclusion.

Wang, X.; Guan, J. (2017) Financial inclusion: measurement, spatial effects and influencing factors, Applied Economics, Vol. 49, № 18, pp.1751-1762.

Yangdol, R.; Sarma, M. (2019) Demand-side factors for financial inclusion: A cross-country empirical analysis. International Studies, Vol. 56, No 2-3, pp. 163-185.

Zubeldia, A. M.; Grajirena, J. M.; Sogorb, A. O.; Zubiaurre, M. Z. (2008) Reflexiones sobre el origen y las implicaciones de la exclusión financiera. In Universidad, Sociedad y Mercados Globales (pp. 209-218). Asociación Española de Dirección y Economía de la Empresa (AEDEM).

Zubeldia, A. M.; Grajirena, J. M.; Zubiaurre, M. Z. (2012) El estado del arte de la exclusión financiera. Revista Icade. Revista de las Facultades de Derecho y Ciencias Económicas y Empresariales, No 85, pp. 51-62. 